\title{
Saving More in Groups: Field Experimental Evidence from Chile*
}

\author{
Felipe Kast ${ }^{\dagger} \quad$ Stephan Meier ${ }^{\ddagger} \quad$ Dina Pomeranz ${ }^{\S}$
}

April 2016

\begin{abstract}
We test the impact of a peer group savings program on precautionary savings, through two randomized field experiments among 2,687 microcredit clients. The first experiment finds that the Peer Group Treatment, which combines public goal setting, monitoring in the group, and non-financial rewards, increases savings in a new savings account significantly. The number of deposits grows 3.7 -fold, and the average savings balance almost doubles. In contrast, a more classical measure, a substantially increased interest rate, has no effect for most participants and raises the savings balance only for the very top of the distribution. A second experiment, conducted a year later, tests an alternative delivery mechanism and shows that effects of similar size can be achieved through feedback text messages, without meetings, rewards, or peer pressure.
\end{abstract}

JEL classification: D03, D14, D91, O16

\footnotetext{
${ }^{*}$ This paper was previously circulated under the title "Under-Savers Anonymous: Evidence on Self-Help Groups and Peer Pressure as a Savings Commitment Device."

${ }^{\dagger}$ Centro de Estudios Horizontal, 636 Esmeralda St. Santiago, Chile.

${ }^{\ddagger}$ Columbia University GSB and NBER, 710 Uris 3022 Broadway, New York, NY 10027. sm3087@columbia.edu.

${ }^{\S}$ Corresponding Author. Harvard Business School and NBER, Rock Center 213, Soldier's Field Boston, MA 02163. dpomeranz@hbs.edu.
} 


\section{Introduction}

Peers can have both negative and positive effects on human behavior. The use of peers as a commitment device to reach a shared but individual goal is a widely observed phenomenon, both informally (e.g., running groups or study groups) and formally (e.g., weight-loss groups). On the other hand, peer pressure can also lead individuals to make sub-optimal decisions (e.g., Bishop, 2006; Kremer and Levy, 2008). While self-help peer groups have been subject to theoretical analysis (e.g., Schelling, 1984; Battaglini et al., 2005), to our knowledge there exists no clean evidence investigating whether peer groups make participants more likely to increase their savings, and if so, what aspects lead to this effect.

We conducted two randomized field experiments among low-income microentrepreneurs in Chile to study the power of 1) self-help peer groups and 2) peer-related text messages for precautionary savings. Our first experiment, the "Peer Group Experiment," shows that self-help peer groups, which combine public goal setting, monitoring in the peer group and recognition for those who comply, significantly increase savings. We offered 2,687 micro-entrepreneurs, who met regularly in groups as clients of a microcredit association, the opportunity to open a formal savings account. Participants were randomly assigned to one of three conditions: 1) a control condition where individuals were offered a basic savings account, 2) a "Peer Group Treatment" where participants were offered a basic account and additionally had the option to set and publicly announce their savings goals, which was then publicly monitored in the weekly meetings and rewarded with a non-monetary recognition, and 3) a High-Interest Treatment where participants were offered a savings account with a $5 \%$ real interest rate instead of the $0.3 \%$ rate in the basic account.

Participants assigned to the Peer Group Treatment deposit 3.7 times as often into the savings account and their average savings balance is almost twice that of the control group. The treatment-on-the-treated effect on the total amount deposited of 25,900 Chilean pesos (about 52 USD) ${ }^{1}$ represents about $32 \%$ of mean monthly per capita income and corresponds in size to the type of expenditures participants had expressed wanting to build a buffer stock for such as unexpected doctor's visits and payments for heating, electricity or food during periods of short-term income fluctuation. ${ }^{2}$ These expenditures are in line

\footnotetext{
${ }^{1}$ We use the exchange rate at the middle of the treatment period.

${ }^{2}$ In focus groups conducted before the interventions, participants said they frequently regret not
} 
with a precautionary savings model. While the amounts of savings are relatively small in absolute terms, Kast and Pomeranz (2014) show that even such small amounts can have significant effects on consumption smoothing and borrowing needs. Correspondingly, participants in the Peer Group Treatment subsequently claimed to be significantly less anxious about their financial future, consistent with other studies showing that savings can make a substantial difference in participants' lives (e.g., Burgess and Pande, 2005; Ashraf et al., 2010; Brune et al., 2011; Dupas and Robinson, 2013a,b).

However, it is unclear whether the increased savings are welfare improving for our sample. To make such a claim, we would need evidence that participants were not already at an optimal level of savings. ${ }^{3}$ Large amounts of savings would arguably be sub-optimal for a population that is borrowing at the same time. A certain buffer of precautionary savings may be valuable in specific cases. For example, because of the different liquidity of savings and loans (Zinman, 2007), the rigid schedule of the micro-loans may render those loans unsuitable for covering irregular or unexpected financial needs (Karlan and Mullainathan, 2009). ${ }^{4}$ This question is beyond the scope of this paper. While we are agnostic about whether saving more is welfare increasing for these participants, the setting can nonetheless shed light on savings behavior.

In contrast to the effect of the Peer Group Treatment, the strongly increased interest rate has a surprisingly small effect - even though it was made exceptionally salient. While average savings increase somewhat, the vast majority of participants do not appear to respond to the interest rate at all. However, because the null result on the overall mean is quite noisy, particularly in the non-winsorized specification, it has to be interpreted with care.

Our second "Feedback Message Experiment" was conducted one year after the opening of the study accounts. After having detected the overall effects of the Peer Group Treatment, the Feedback Message Experiment was implemented to disentangle some of

having saved more and many mentioned the goal of building savings as a buffer stock for emergencies. Participants additionally mentioned that the extra savings need to come from decreases in spending on temptation goods and reduced borrowing. The groups that participated in the focus groups were not included in the randomized evaluation.

${ }^{3}$ In other settings, it seems that households are quite good at making optimal decisions about saving vs. borrowing (Telyukova, 2013; Zinman, 2015). For a more detailed discussion, see Section 2.1.

${ }^{4}$ The cost of having liquid savings at the same time as loans is represented by the interest rate on the loan. In this context, the cost of the loan can be thought of as an insurance premium paid for having liquid savings. In the case of Fondo Esperanza (FE), this is a $3 \%$ monthly interest rate and a $3 \%$ fixed fee. We discuss this further in Section 2.1. 
the mechanisms and gain greater insights into which components are required for effectiveness. The Peer Group Treatment consisted of a bundle of different, potentially important elements. The Feedback Message Experiment strips the treatment of many of these aspects in order to get more information about what might be driving the effect. However, as we discuss below, it is still a bundle of several components.

The Feedback Message Experiment was implemented among a sample of 871 participants who had opened an account in the Peer Group Experiment, owned a cell phone and were interested in a text message service to help them save more. Participants were assigned to one of three groups: 1) A "Peer Pressure" weekly Feedback Message Treatment with a real-life Savings Buddy who was also regularly informed about the performance of the participant; 2) A "Peer Information" weekly Feedback Message Treatment with information about savings by others; 3) A control group in which participants did not receive any text messages. Compared to the Peer Group Treatment, the Feedback Message Experiment removes in-person meetings, stickers, rewards and any group dynamics. It also holds goal setting constant across treatments and control. The Savings Buddy retains the element of peer pressure - others observing the performance of the participant (Schelling, 1984) - while the Peer Information Treatment retains the element of observing the performance of others (Battaglini et al., 2005).

Surprisingly, we find that the feedback message with a Savings Buddy has no larger effect than the Peer Information Treatment that simply informs participants of their own achievement and the success rate of other participants. These results provide suggestive evidence that neither in-person meetings nor peer pressure are indispensable features of the Peer Group Treatment. Even though the findings from the two separate experiments cannot be directly compared, because the populations and time periods are different by design, the results suggest that holding people accountable through regular feedback and follow-up messages may increase savings almost as much as the Peer Group Treatment. The Feedback Message Experiment suggests that modern technology - in the form of text messages or other feedback devices - has the potential to render the accountability mechanism of the Peer Group Treatment more scalable and potentially more attractive to larger and different populations.

This paper makes contributions in three areas. First, it speaks to the literature on commitment devices for saving. While much of the literature on savings commitment devices in developed countries has studied deposit commitment devices (e.g., Madrian and Shea, 2001; Thaler and Benartzi, 2004; Carroll et al., 2009), most of the literature 
on developing countries has focused on withdrawal commitment devices (see, e.g., Ashraf et al., 2006b; Brune et al., 2011, and Bryan et al., 2010 for a review article). With the notable exception of Ashraf et al. (2006a), who study the determinants of take-up for deposit collectors in the Philippines, our paper provides one of the first analyses of the effectiveness of a deposit commitment device for developing countries. ROSCAs (Gugerty, 2007; Dupas and Robinson, 2013b) are an interesting hybrid case. Their strict deposit and withdrawal schedule generates both a deposit and withdrawal commitment device, and during different phases of the cycle, they function as a savings- and later a creditvehicle. Deposit commitment devices with liquid accounts are particularly important for precautionary savings, since in contrast to withdrawal commitment devices, the savings are always available in times of need. This limits the risk that the commitment device creates welfare losses if an emergency arises. This paper demonstrates the effectiveness of a deposit encouragement device that does not rely on a formal wage bill, and is therefore available to those working in the informal sector, the unemployed or independent entrepreneurs. We are agnostic about whether the underlying mechanism for this effectiveness stems from commitment or other channels such as attention.

Second, this paper provides evidence on the role of a Peer Group Treatment as a means of encouraging a particular behavior more generally. Peer effects have been widely shown to affect behavior, for example, with respect to productivity at work (e.g., Falk and Ichino, 2005; Mas and Moretti, 2009; Bandiera et al., 2010), alcohol consumption (e.g., Kremer and Levy, 2008), and financial decision-making (e.g, Duflo and Saez, 2002, 2003; Bursztyn et al., 2012; Mugerman et al., 2014). Individuals can use these effects strategically to overcome self-control problems by joining self-help peer groups. Despite the large prevalence of self-help peer groups in many domains, there is surprisingly little evidence evaluating their effectiveness. ${ }^{5}$ Our findings show that our Peer Group Treatment can provide a way in which individuals can leverage their peers to support them towards an individual but mutually shared goal. After having found an effective policy to increase precautionary savings, it is helpful to understand what mechanism might be driving the result, in order to gain a better understanding about how the policy might be implemented or scaled most effectively (Ludwig et al., 2011).

The Feedback Message Experiment takes a step in that direction. It starts to un-

\footnotetext{
${ }^{5}$ Walsh et al. (1991) compare the effect of AA meetings to a hospital treatment. The effect of AA meetings per se is not tested, however. Jebb et al. (2011) show that a commercial Weight Watchers (WW) program is more effective than a standard program of care for obese individuals.
} 
bundle some of the mechanisms and at the same time provides an alternative delivery mechanism for the service provided by peer group meetings, which proves to be almost as effective. Combined with evidence that information about the savings behavior of peers could lead to oppositional reactions (Beshears et al., 2015) ${ }^{6}$ and that simple regular reminders can increase savings (Karlan et al., 2016) ${ }^{7}$, the results suggest that the regular feedback and follow-up could be more important to the success of the Peer Group Treatment than the peers themselves.

Third, our finding that a large majority of participants do not increase savings when interest rates are substantially higher and do not adjust their savings portfolio towards the higher return account have implications for the literature on the elasticity of intertemporal substitution and for models and policies based on individuals' responsiveness to the interest rate. In addition to serving as a benchmark for the effect of peer groups, estimating the interest rate elasticity of savings is interesting in and of itself as it constitutes a key variable for many public policies. There is surprisingly little evidence on this question (exceptions include Schaner (2011) in Kenya, and Karlan and Zinman (2014) in the Philippines). ${ }^{8}$ The results on the interest rate also contribute to the discussion of the relative impact of "social" or behavioral versus monetary incentives (e.g., Bertrand et al., 2010; Ashraf et al., 2012; Chetty et al., 2013). The finding that the interest rate has limited effectiveness for most individuals fits into a larger pattern of evidence showing the relative effectiveness of social incentives versus monetary rewards for behavioral change (Gneezy et al., 2011). The effect of the interest rate may be different depending on the purpose of the savings, e.g. for long-term investments such as pension savings, it may matter more than for precautionary savings.

The remainder of the paper is organized as follows: Section 2 presents set-up and design of both field experiments. Section 3 and 4 show the results of the Peer Group

\footnotetext{
${ }^{6}$ The evidence on peer information is in general mixed. While positive effects have been found in some domains, such as electricity usage when bundled with tips to save energy (Allcott, 2011; Ayres et al., 2012) or contributions to public goods (e.g., Frey and Meier, 2004; Chen et al., 2010; DellaVigna et al., 2012), peer information has been shown to reduce work effort (Barankay, 2010) or lower take-up of tax credits (Manoli and Bhargava, 2011). For a discussion in psychology about the ambiguous effects of peer information, see Schultz et al. (2007).

${ }^{7}$ Reminders have also been found to be effective in other areas, for example to decrease overdraft bank fees (Stango and Zinman, 2011), or to improve books returns to the library (Apesteguia et al., 2013), repayment of loans (Cadena and Schoar, 2011), goal achievement in the workplace (Cadena et al., 2011), vaccination rates (Milkman et al., 2011), and energy efficiency and conservation (Harding and Hsiaw, 2011).

${ }^{8}$ Duflo et al. (2006), Mills et al. (2008) and Engelhardt and Kumar (2009) analyze the effect of matching contributions to individual savings plans.
} 
Experiment and the Feedback Message Experiment respectively. Section 5 compares the Peer Group Treatment with the High-Interest Treatment. Section 6 concludes.

\section{Background, Data, and Design of Experiments}

\subsection{Background and Data}

Both randomized field experiments for this study were conducted in collaboration with the microfinance institution Fondo Esperanza (FE), and a large commercial bank, Banco Credichile. The context of FE is particularly suitable to analyze the role of self-help peer groups for savings by those outside the formal labor market. The study participants were microcredit clients of FE, and the savings accounts that were offered were held with Banco Credichile. FE's clients are self-employed micro-entrepreneurs (e.g., street vendors, cosmetic saleswomen), many of whom work in the informal sector. Participants are typically from the same geographic area but do not work together as each has their own micro-entreprise. They meet regularly, on a weekly or biweekly basis, in groups of about 10-20 peers, together with a group supervisor from FE. The purpose of the meetings is to enforce the regular repayment of the micro-loans that participants receive from FE in 3-month cycles for investment in their micro-enterprise. This feature allowed us to incorporate the peer group-based program features and structure.

The participants in this study fall in the lowest of the three tiers of income categorizations developed by the Central Bank of Chile. Data from a household survey conducted in 2008 by the central bank finds that $64.5 \%$ of those in the lowest income group have some amount of debt (Gerencia de Investigacion Financiera, 2013). ${ }^{9}$ Median household debt for the lowest income group in the central bank survey was 370,000 Chilean pesos, while the individuals in our sample have a median debt of 264,000 pesos. The amounts of debt between the two samples are not directly comparable because they are recorded at the household level in the central bank survey while our data is at the individual level. Although the fact remains that all participants in our study held some form of debt with $\mathrm{FE}$, the amounts of total debt suggest that their overall borrowing may not be unusually high.

\footnotetext{
${ }^{9}$ The median household income in the lowest tier is 281,667 Chilean pesos (CLP) compared to 291,734 in our sample.
} 
Given that our participants are all borrowing from the microfinance organization, the treatment encourages people to save while borrowing. Simultaneously saving and borrowing may not be optimal because instead of saving (and receiving a low interest rate), participants could reduce their debt (which has a higher interest rate). Several conditions must hold for increased savings to be welfare improving in this setting. ${ }^{10}$ 1) Due to behavioral or credit market frictions, participants have reasons to lend low and borrow high. For example, higher liquidity in savings than borrowing could lead households to keep some precautionary savings while borrowing at the same time; 2) Participants do not do this optimally on their own prior to the intervention (maybe due to behavioral reasons); 3) Participants are accepting a negative return in order to overcome their behavioral limitation in saving more; 4) The treatment works to cure under-saving.

We will discuss these conditions in turn. In the end, while some evidence suggests that additional savings may be beneficial for our population, this has to be interpreted with caution. Overall, we are agnostic as to whether increased savings are welfare improving for most participants in our sample.

With respect to whether it is optimal for participants to hold debt and assets at the same time (condition 1 above), Telyukova (2013) shows that people hold (credit card) debt and "low return liquid assets" (such as cash in the bank) because of transaction frictions (see also the evidence in Zinman, 2007). She finds that a substantial fraction of households keep cash because they anticipate situations where they cannot use their credit card and will therefore need to access their liquid assets. Whether our participants face such borrowing frictions is difficult to judge. However, the structure of the loans at Fondo Esperanza has a very rigid schedule of payments. No extra borrowing in times of emergencies is possible until the next scheduled round of lending (every three or six months, depending on the group). As such, participants may want to keep some precautionary savings because they provide households with liquid assets in case of unexpected need.

Even if it is optimal for our participants to have some savings while borrowing, for an intervention to be warranted there need to be barriers that prevent participants from reaching their optimal level on their own (condition 2). The existing evidence indicates that households are often optimally allocating between savings and debt (see Zinman, 2015, for an excellent review). On the other hand, behavioral factors can also lead to

\footnotetext{
${ }^{10}$ We thank an anonymous referee for suggesting these specific conditions.
} 
under-saving for emergencies - Dupas and Robinson (2013b), for example, find that even quite basic savings technologies like earmarking can address behavioral issues that previously prevented participants from saving for health emergencies. We only have suggestive evidence that our participants had difficulties saving optimally. In the baseline survey, participants were asked whether there were times in the past three months in which they regretted not having saved more. Among the options (always, frequently, almost never, and never) $39 \%$ said always, and 29\% said frequently. In other words, $68 \%$ regretted not saving more. However, the survey did not ask specifically whether they regretted not saving more while borrowing from FE. If they would have been asked specifically about the trade-off, they might have wanted to reduce debt instead of saving more. The only indication that we have of participants' views on how they wanted to save more stems from focus groups prior to treatment. In these qualitative interviews, participants consistently expressed that increasing savings required budgeting changes on other margins. They stated that they wished to cut down consumption from non-planned expenditures, particularly temptation goods (e.g., candy on the way to work) so that they could save more.

Additional suggestive evidence on the question whether participants were already at their optimal savings level stems from the finding that the treatment had positive effects in terms of anxiety about participants' financial future (see section "Are These Real Additional Savings?"). However, overall we do not have conclusive information on whether participants were at sub-optimal savings levels prior to the intervention.

To get a sense of the price participants are willing to pay to hold liquid savings while having debt (condition 3 above), we can ask how costly it is for participants to increase their savings instead of paying down debt. We calculate how much participants could have reduced their interest payments if they reduced their debt by the additional savings due to the treatment. FE charges a $3 \%$ monthly interest rate and a one-time $3 \%$ fixed fee per loan cycle. Participants in the Peer Group Treatment would have paid 348 Pesos (about 70 cents) less interest over a three-month lending period had they used their additional average monthly savings balance (4,050 Pesos) to lower the amount that they borrowed. The final condition (4) - whether the treatment worked to increase savings - is addressed by the main results of the paper showing the impact of the Peer Group Treatment on savings.

This paper draws on three different sources of data. First, information on take-up and all transactions (i.e., deposits, withdrawals and balances in the accounts) was obtained 
directly from Banco Credichile. Based on the deposit and withdrawal data from Banco Credichile, we calculated balances (deposits minus withdrawals). In doing so, we did not add interest rate payments. Since the bank provided this information for all participants, there is no attrition in the data. The second source of data came from FE's administrative files, which include participants' estimated household size, income, and years of education. Unfortunately, data on loan size or default rates was not available. Finally, we complemented these two sources of administrative data with an extensive baseline and follow-up survey, conducted by the independent survey agency Microdatos. These surveys include questions about participants' savings and debt, their economic situation and recent economic difficulties, as well as a number of questions about individuals' preferences and self-assessment, such as attitudes towards savings and banks, financial literacy, time preferences, etc.

The timeline of the interventions was as follows (see Figures 1 and 2 for an illustration): The baseline survey was conducted in April-May 2008, during one of the group meetings. The savings accounts for the Peer Group Experiment were introduced soon after, in June-July 2008. A year later, the follow-up survey was conducted through individual interviews at participants' home or workplace to be able to cover all participants, including those that had left FE in the meantime. During this follow-up survey, eligible participants were introduced to the second experiment, the Feedback Message Experiment.

[Figures 1 and 2 about here.]

\subsection{Experiment 1: Peer Group and High-Interest Treatments}

\section{Design}

The Peer Group Experiment analyzes the effect of the self-help Peer Group Treatment on savings and compares it to a control group as well as a benchmark group with a substantially higher interest rate. The experiment was conducted among 196 peer groups with a total of 2,687 clients of the microcredit organization Fondo Esperanza (FE). The universe of study participants consists of all members of the 196 groups who were present at the meeting when the baseline survey was conducted.

Participants in all three groups - Control, Peer Group Treatment and High-Interest Treatment - were offered a savings account. Prior to the introduction of the account, 
a baseline survey was conducted. In the following weeks, peer groups were randomly assigned to either the control group or one of two treatment groups (see Figure 1 for a graphical representation of the experimental design). All members within a peer group were offered the same treatment without learning of the other treatments. The randomization was stratified by group supervisor, which automatically led to balance by region as well. Half of the groups were randomly selected for the Peer Group Treatment, while the rest were assigned to the high interest rate and the basic account groups in equal proportion. $^{11}$

1. Control Group: Participants assigned to the control group received access to a basic savings account. Information about the savings account was presented in one of the regular group meetings. Participants could open the account at Banco Credichile on their own or go to the bank together with their peers. All accounts were individual. These savings accounts had a real annual interest rate of $0.3 \%$ (similar to the highest standard alternative in the Chilean market). It was attractive compared to generally available options in the market in that it had no maintenance fee and no minimum balance, except for a 2-dollar minimum opening deposit. The account was completely liquid for withdrawals at any time, and the financial conditions were guaranteed for at least two years.

2. Peer Group Treatment: Participants in the Peer Group Treatment received access to the same basic bank account as those in the control group. This was accompanied by the following peer group structure: 1) Group members who opened an account had the option of announcing a weekly deposit goal for the following three months to the group; ${ }^{12}$ 2) During the following group meetings, participants checked who had met their deposit goal, based on deposit slips that participants brought to the meeting; 3) Those who had met their goal received a sticker in a booklet; 4) Those who collected enough stickers received a diploma as a non-monetary award. The stickers assisted in keeping track of progress, but there were no financial incentives for complying with one's goal.

3. High-Interest Treatment: Participants in the High-Interest Treatment received access to an account that was identical to the basic account, but were offered a $5 \%$

\footnotetext{
${ }^{11}$ The design also included a pure control group that received no savings account, used for an impact evaluation of access to a formal savings account (discussed in Kast and Pomeranz, 2014).

${ }^{12}$ While it might be of interest to have more information about participant's savings goals, this data has not been provided by FE.
} 
real interest rate. It was explicitly presented as the "Most Profitable Interest in the Market." The introduction of the account was accompanied by a one-hour workshop during the group meeting about the importance of interest rate returns. The high return was illustrated graphically with a growing piggy bank and a representation of compounded interest rates.

\section{Summary Statistics}

Table 1 presents summary statistics for the 2,687 participants in the sample of the Peer Group Experiment. As expected, given the random assignment, average characteristics in the three treatment groups are very similar and there are no statistically significant differences with the exception of group size.

[Table 1 about here.]

Participants in the study are an average of 43 years old and have a mean of 9.7 years of schooling. Monthly income per capita of their households is 80,519 pesos (about 161 USD), with an average household size of 4.3 people. Sixty-seven percent of participants did not have a savings account prior to the study. ${ }^{13}$ Correspondingly, the median of preexisting savings was zero, with a mean of 68,980 pesos (while income is expressed in per capita terms, these savings may combine savings of several household members, especially including participants' children). Participants' reported mean debt, including the microloan from FE, is 287,326 pesos, with a median of 66,000 pesos. The larger amounts of debt compared to savings is not surprising given that participants are entrepreneurs and most of their debt is backed up by inventories and future sales. The average number of participants was 15 per group with a slightly lower average in groups offered the basic savings account. ${ }^{14}$

\subsection{Experiment 2: Feedback Messages}

The Feedback Message Experiment was designed as a follow-up study to the Peer Group Experiment. Since the Peer Group Treatment consisted of a whole bundle of different, potentially important elements, the goal of the Feedback Message Experiment was to

\footnotetext{
${ }^{13}$ In Chile in general, $40 \%$ do not have a bank account (Demirgüç-Kunt et al., 2008, p. 190).

${ }^{14}$ The baseline survey was conducted before it was determined which groups were going to be assigned to which treatment, so we can exclude a selection effect based on the type of the account.
} 
strip the treatment of several of these aspects. It keeps many things constant, in order to advance our understanding of what drives the effect and investigate an alternative, potentially more scalable delivery mechanism.

This second experiment was conducted one year after the Peer Group Experiment began, soon after the follow-up survey. Eligible participants were randomly assigned to either the control group or one of two weekly text message service treatments designed to simulate the regular feedback and follow-up of peer group meetings (see Figure 2 for a graphical representation of the experimental design). ${ }^{15}$ All participants, including those in the control group, were asked to state a purpose for which they wanted to save in the following three months and to set a weekly savings goal towards that purpose. This allowed us to keep the goal setting aspect constant across both treatments and control. ${ }^{16}$ The two treatments were as follows:

1. Treatment 1: Peer Pressure Treatment - Participants chose a person as their "Savings Buddy" to monitor their performance and encourage them to stick to their savings goal. Both the participant and the Savings Buddy subsequently received weekly text messages about whether the participant did or did not make their deposit that week and the message reminded participants that the Savings Buddy received the same information (see Appendix A for exact wording of the messages).

2. Treatment 2: Peer Information Treatment - In the same way as in Treatment 1, participants received a weekly text message about whether they made their weekly deposit. However, there was no Savings Buddy involved; only the participant received text messages. Instead, participants were informed about the share of other participants similar to them who made a deposit that week. ${ }^{17}$

These treatments allow us to hold more things constant than the Peer Group Treatment. There are no stickers, rewards or group meetings, and non-public goal setting is held

\footnotetext{
${ }^{15}$ After a welcome text message was sent, participants also got a phone call reminding them that they will receive weekly text messages.

${ }^{16}$ With respect to goal setting, Soman and Zhao (2011) find that a single savings goal (e.g., to save for the education of one child) increased savings substantially compared to having multiple savings goals.

${ }^{17}$ The design of the Peer Information Treatment in principle also allowed analyzing the impact of varying quality of peers, by introducing random variation in which peers participants were compared to. We assigned participants to "comparison" groups in order to create random variation in peer quality. This makes it possible to test whether participants who are informed about a different level of success of their peers in their first week of treatment display a different deposit pattern thereafter. However, power limitations did not allow distinguishing such differential treatment effects.
} 
constant across treatment and controls. The difference between the two Feedback Message Treatments relates to the following: Peer groups are often thought to affect behavior by creating pressure on individuals (e.g. Schelling, 1984). ${ }^{18}$ Alternatively, Battaglini et al. (2005) suggest that participants of the Peer Group Treatment may be motivated by observing the success of others. In addition to the regular feedback, one Feedback Message Treatment therefore included the aspect of peer pressure - others observing the success rate of the participant - while the second treatment included the aspect of the participant observing the success rate of others. However, since both Feedback Message Treatments serve as reminders as well, we cannot distinguish the impact of the Peer Pressure and Peer Information treatments from the effect of a pure reminder. It is therefore difficult to tease out the exact mechanisms that drive the results.

\section{Sample Selection and Set-Up of the Intervention}

The sample of the Feedback Message Experiment consisted of the participants who had opened an account as part of the Peer Group Experiment, of which those who did not own a cell phone or opted out of the service were excluded. Assignment into the different treatment arms and control in the Feedback Message Experiment was stratified by treatment group in the Peer Group Experiment. ${ }^{19}$ This led to a sample of 871 participants (see below for how those participants differed from the full sample of the Peer Group Experiment). About half of the participants had previously taken part in the Peer Group Treatment, and we can test whether the results of the Feedback Message Experiment are different depending on treatment status in the first experiment.

Prior to administering the follow-up survey, all participants who opened a savings account during the first experiment were randomly assigned to one of the two treatment groups or to the control group for the second experiment. The randomization was stratified by savings balance in the study account and by the group to which participants belonged. The latter automatically assures stratification by treatment in the first experiment. To maximize take-up, a set of screening questions was asked during the survey to exclude those who did not own a cell phone or were not interested in the weekly text message service to help them save more.

All participants, including the control group, were asked what their weekly savings goal would be for the next three months if such a service were offered. Since this question

\footnotetext{
${ }^{18}$ For a similar argument about norm adherence, see, e.g., Bernheim (1994) and for image motivation, see Benabou and Tirole (2006); Ariely et al. (2009).

${ }^{19}$ See Appendix B for the wording of the screening questions.
} 
was asked prior to the assignment of treatment and worded exactly the same regardless of treatment, we can rule out that the effect is driven by the process of goal-setting itself (see e.g., Locke and Latham, 2006; Hsiaw, 2013). Those assigned to one of the treatments were then informed that they could indeed receive such a service for free, and the details of their particular service were explained (without mention of the existence of other treatments). Since the interviews happened in a staggered manner, different participants started receiving the service at different points in time. However, the service ended for everyone at the same time (at the end of October 2009).

\section{Summary Statistics}

Table 2 presents summary statistics of the Feedback Message Experiment. As expected, given the random assignment, average characteristics across treatment groups are very similar.

[Table 2 about here.]

Similar to the Peer Group Experiment, participants have an average of 9.7 years of schooling, their mean age is 44 years, and $66 \%$ did not have a savings account prior to the account they opened in the context of this study. The mean monthly per capita income of participants' households is 82,636 Chilean pesos (about 165 USD) with a median of 70,000 pesos. The average number of household members is 4.4. The average savings balance in the study accounts at the beginning of the Feedback Message Experiment is 12,759 pesos and participants made an average of 1.52 deposits and 0.70 withdrawals during the 12 months preceding the Feedback Message Experiment. Participants in the Feedback Message Experiment are similar along demographic variables to those who were in the overall sample of the Peer Group Experiment but did not participate in the Feedback Message Experiment. However, their median income at baseline (prior to any treatment) is about $5 \%$ higher and their median financial debt is about $19 \%$ higher (on the other hand, their mean financial debt is about $23 \%$ lower ). In addition, they had used the study account more actively by construction, since only those who had opened an account during the Peer Group Experiment were included in the Feedback Message Experiment. 


\section{The Effect of the Peer Group Treatment on Savings}

This section analyzes the effect of the Peer Group Treatment on savings compared to the control group, which was offered a savings account without the additional goal setting, monitoring, and rewards program that functioned in the context of the peer groups ("Peer Group Treatment" thereafter). Figure 3 shows the effect of the Peer Group Treatment on the monthly number of deposits and average savings balance. It displays the intent-totreat (ITT) effect for 12 months starting in August 2008, after the opening period of the accounts (June-July 2008). It compares those assigned to the Peer Group Treatment to those assigned to the basic account. The Peer Group Treatment clearly increases savings both in terms of number of deposits and amount deposited. Panel A shows that the number of deposits is almost four times higher in the Peer Group Treatment. While the effect strongly decreases over time, even in the last quarter of the year, the number of deposits is still over three times higher (0.059 vs. 0.016; $p<0.001$ ).

[Figure 3 about here]

Panel B of Figure 3 shows how the Peer Group Treatment not only increases the number of deposits but also leads to higher savings balances. The average balance is twice as high for participants in the Peer Group Treatment as in the control group. The effect persists over time and does not decrease during the entire year. The fact that savings increase initially and stay constant afterwards suggests that individuals may have reached a stable level of savings that they maintain, consistent with a precautionary savings model. Before building any savings beyond a small buffer stock, it would be in their interest to first reduce their debt. For this reason, it is expected that the amount saved will be relatively small in magnitude.

The decrease in the number of deposits over time might also be explained by at least three other reasons. First, individuals might not continuously participate in the Peer Group Treatment, for example if they leave FE. Individuals in the Peer Group Treatment who are still with FE one year after the introduction of the accounts make more deposits throughout the intervention period. However, this correlation has to be interpreted with caution since who stayed or left is clearly not exogenous. Second, the FE group leader and/or participants might lose some of the initial motivation, and the quality and regularity of the monitoring of savings goals in the meetings might consequently 
decline over time. ${ }^{20}$ Third, maybe participants shift large amounts from other savings vehicles to the study account during the initial months. Looking at the share of large deposits (higher than 25,000 pesos), shows that the share of individuals who made such large deposits in the first three months is $3.5 \%$ in the basic account treatment and $5.4 \%$ in the peer group treatment.

Table 3 shows these results in an OLS framework. ${ }^{21}$ We estimate regressions of the following specification:

$$
S_{i}=\alpha+\beta_{1} \text { Self Help } \text { He }_{i} \text { Interest Rate }_{i}+\epsilon_{i}
$$

$S_{i}$ is the savings outcome for individual $i$. We analyze three savings outcomes, starting in August 2008: (1) the number of deposits over 12 months, (2) the total amount deposited, and (3) the average monthly balance. In order to illustrate the effect of outliers, we also show the results for a sample that is winsorized at top $1 \%$ and top $5 \%{ }^{22}$ Self Help is a dummy equal to one for individuals in the Peer Group Treatment and Interest Rate is a dummy equal to one for those in the High-Interest Treatment. $\epsilon$ is the error term. This section focuses on the analysis for the Peer Group Treatment, compared to the basic account. Section 5, below, compares these effects to the results for the High-Interest Treatment as a benchmark.

Panel A of Table 3 presents the intent-to-treat (ITT) effect for all three outcomes. The ITT effects support the findings of Figure 3: the number of deposits, the amount deposited, and the savings balance are significantly higher for those in the Peer Group Treatment. Panel B shows treatment-on-the-treated (TOT) effects. For the purposes of

\footnotetext{
${ }^{20}$ Group leaders were trained to conduct the activities for the Peer Group Treatment during the group meetings. We cannot measure to what degree these activities were followed through more intensely in the first few months since we have insufficient information on how the weekly meetings proceeded. A reduction in intensity of the actual treatment over time is consistent with the fact that savings drop off after the first few months in the Peer Group Experiment but remain more constant in the Feedback Message Treatment (see Figures 3 and 4). It is also possible that at the start of the program participants were more diligent at actively participating. At the end of the Peer Group Experiment, we asked participants about the implementation of the group activities (see Appendix Table A1). The majority of respondents reported that the group leader motivated the group to save and used the form to track progress in every meeting and that nobody received a sticker without showing proof of deposit with a deposit slip. Awards were distributed in about half the groups. However, this does not give us any indication about the dynamics over time.

${ }^{21}$ Tobit specifications do not change the results qualitatively.

${ }^{22}$ The winzorized dataset sets the top $1 \%$ and $5 \%$ of the observations, respectively, to the 99th and 95th percentile value using the entire dataset, including the period of the first and second experiment combined.
} 
this specification, we consider participants to be "treated" if they opened a study account and made at least one deposit. We do not have data on who elected to actively participate in the group treatment by publicly announcing their savings goal and progress. Since some participants may not have participated in the peer-related activities, these TOT effects provide a lower bound on the impact of these activities. Take-up rates of the savings accounts are very similar across the three treatments. $49.7 \%$ of participants opened an account among those offered the basic account, 54.7\% among those in groups assigned to the Peer Group Treatment, and 50.7\% among those offered the high interest rate account (the differences are not statistically significant). Correspondingly, Panel B shows that the TOT effects are about twice the size of the ITT effects.

[Table 3 about here.]

These effects are both statistically and economically significant, as the number of deposits increases 6 -fold and the average savings balances almost triple. The TOT increase in total amount deposited over the course of a year of 25,937 pesos represents about $32 \%$ of mean monthly per capita income and corresponds in size to the precautionary savings goal mentioned in the focus groups. The increase in the number of deposits by 1.5 masks a substantial heterogeneity among participants: $53.5 \%$ of participants in the Peer Group Treatment who opened an account made zero deposits beyond the minimum opening amount in the entire year, while $5.4 \%$ made at least 10 deposits over the year. ${ }^{23}$ To put our results in perspective, Dupas and Robinson (2013b) test the effect of social pressure on savings in their Health Pot treatment. In a ROSCA (Rotating Savings and Credit Association) setting, participants could make contributions to a side pot that could only be used for health expenditures. Through the ROSCA mechanism, there was social pressure and all but the last member received the health product earlier than if they had saved individually (i.e., they got credit). The Health Pot increased savings by 128-138 percent.

In sum, the evidence indicates that the Peer Group Treatment is effective at encouraging deposits, which in turn leads to increased savings balances. The increased number

\footnotetext{
${ }^{23}$ Evidence from e.g. Ashraf et al. (2006b) and Meier and Sprenger (2010) suggests that individuals who exhibit time-inconsistent preferences might benefit particularly from financial commitment devices. In our context, the Peer Group Treatment led to front-loading of the cost of not saving, which may have a particularly strong effect on those with time-inconsistent preferences. Table A2 in the Appendix explores differential treatment effects along this category, and the evidence indeed suggests that the treatment might be particularly effective for those with time-inconsistent preferences.
} 
of deposits is not offset by a corresponding increase in withdrawals, even though the accounts are fully liquid and withdrawals are not observable by the peers.

\section{Are These Real Additional Savings?}

Having found that the Peer Group Treatment doubles savings in the study account, it is important to ask whether this constitutes additional savings or just crowds out other forms of savings. Generally, it is very difficult to obtain evidence on this question since researchers usually only have information about one savings vehicle, and survey data on total savings tends to be very noisy. Keeping this caveat in mind, most previous studies that tested for this found no evidence of crowd-out, or even some evidence for crowding in (e.g. Ashraf et al., 2006b; Gelber, 2011; Prina, 2012; Dupas and Robinson, 2013a,b). Chetty et al. (2013) find that nudges such as automatic contributions by employers do not crowd out retirement savings. In contrast, a tax subsidy as a financial incentive for savings crowds out other savings almost one-to-one. However, in our case, we cannot conclusively demonstrate that the savings constitute additional savings, we can only provide a number of suggestive facts.

First, for the $67 \%$ of participants that did not have another savings account, savings in the study account represents all new formal savings. To look at all forms of savings, including informal savings, we use data from the follow-up survey. However, this data is very noisy and does not allow for strong conclusions. ${ }^{24}$ Correspondingly, none of the following results are statistically significant. Anticipating the noisiness of self-reported amounts, we also elicited a binary measure where participants indicated whether they made deposits or withdrawals from any other account in the previous six months. This measure is less noisy since it is easier for participants to remember than exact amounts. ${ }^{25}$ Columns (1) and (2) of Table A3 in the Appendix show that those in the Peer Group Treatment are not less likely to use other accounts, both in terms of deposits and withdrawals. Columns (3)-(5) show the results on total formal savings (Panel A) and overall

\footnotetext{
${ }^{24}$ To get a sense of how noisy the self-reported information is, we compare the self-reported amount for the study account with the correct amount in the account, which we know from administrative data, and find a correlation of merely 0.43. It is also surprising that many individuals indicate that they do not have money in any form. For example, $58 \%$ indicate that they do not have any money saved at home or in their business. The results of this section changed somewhat compared to previous versions, since we realized while doing robustness checks that some of the very large amounts, which led to noisy estimates, were in fact data entry errors and had to be coded as missing.

${ }^{25}$ Confirming the validity of this measure, we test whether participants in the Peer Group Treatment reported a higher probability of having made a deposit into the study account, which we know from the administrative data to be true, and find that this is indeed the case $(p<0.01)$.
} 
savings (Panel B) for varying degrees of winsorizing. Again, none of the effects are statistically significant. Finally, Table A4 in the Appendix shows a similar picture for the effects on each components of overall savings.

A second indicator on whether the study account has real impacts and does not only replace other savings stems from evidence in Kast and Pomeranz (2014). That paper analyzes the impact of access to any of the study accounts compared to a control group, which was not offered any account. Having access to a study account helps participants alleviate the burden of economic shocks, both objectively and subjectively. After one year, participants with access to the study accounts have $24 \%$ fewer outstanding payments to service providers $(p<0.01)$ and $37 \%$ fewer outstanding payments to family and friends $(p<0.05)$. Furthermore, their need to cut back consumption in times of economic difficulty is reduced by $44 \%(p<0.05) .{ }^{26}$ Subjectively, they report being significantly less anxious about their financial future, and evaluate their recent economic situation as less severe. The magnitudes of these subjective improvements correspond in size to more than half of the change in these measures associated with a job loss or severe business downturn.

The study lacks the statistical power to make very precise statements about the impact of the Peer Group Treatment compared to the other two accounts. Looking at whether the probability of borrowing decreased more for those in the Peer Group Treatment than for those in the High-Interest or basic account groups, there are no large or statistically significant differences (see Table A5 in the Appendix). ${ }^{27}$ In addition, the paper finds that the improvements in anxiety about the financial future are significantly stronger $(p<0.05)$ for individuals in the Peer Group Treatment than for those with access to the basic or high-interest account. ${ }^{28}$ Taken together, this evidence suggests that the

\footnotetext{
${ }^{26}$ While it would be helpful to detect where the additional savings come from, we do not have detailed consumption or revenue data to measure this. We only have information on three specific types of bulky expenditures (home improvements, electronic appliances and business investments). These categories are not significantly affected by the treatment. Similarly, there are no significant effects on the probability of taking on extra work to deal with economic difficulties or the number of people contributing to the household income.

${ }^{27}$ We do not have information about FE loan repayment. We also do not have data on borrowing outcomes following the Feedback Message Experiment, so we cannot speculate as to whether savings in the Feedback Message Experiment came from decreased borrowing.

${ }^{28}$ Please see Kast and Pomeranz (2014) for details and a full discussion of the different outcome variables and the problem of multiple hypothesis testing. In addition to "anxiety about financial future" the followup survey included an additional subjective well-being measure about "recent economic difficulty" for which we do not find a statistically significant effect. This null result might be expected given that participants saved more in the recent past, but we should nevertheless keep in mind that only one of the
} 
savings in our study do not seem to be mere substitution.

\section{How Crucial are Meetings and Peer Pressure?}

The previous section established that the Peer Group Treatment is effective at increasing savings. As mentioned above, the Peer Group Treatment consisted of a whole bundle of interventions including goal-setting, public monitoring, rewards, and observing others save, and cannot distinguish between the effects of these components. It is important to unpack some of these mechanisms to learn which elements are required for the effectiveness of the treatment (Ludwig et al., 2011). In so doing, we may shed light on alternative ways to deliver the service that the Peer Group Treatment provides. This section therefore makes a step towards distinguishing some of these elements. We first analyze whether in-person meetings (and all related activities such as distribution of stickers, diplomas, and moral support) are required, by testing the effectiveness of regular feedback and follow-up in "synthetic" peer groups through text messages. We then investigate whether peer pressure is the driving force by comparing two different types of Feedback Message Treatments - peer pressure text messages via a Savings Buddy vs. peer information text messages.

\section{The Effect of Feedback Text Messages on Savings}

Figure 4 shows the impact of being offered the weekly text message feedback service (either treatment 1 or treatment 2). The horizontal axis represents months since the treatment began in the year 2009, and the area between the vertical lines marks the period during which the text message intervention was implemented (called "intervention period" going forward). Panel A shows the number of deposits per month, and Panel B shows the amount deposited.

[Figure 4 about here]

Figure 4 reveals three important points. First, there is no significant difference between treatment (either kind of text message) and control groups in both panels before the experiment begins in August 2009 (month "1" in the figure). Deposits in June and July two subjective measures was significantly affected. 
trend slightly downward in the cold winter months in Chile, but this trend is no different between treatment and control. Second, during the intervention period, savings outcomes are substantially higher in the treatment compared to the control group, almost tripling the number of weekly deposits. The amounts deposited are more noisy, but even there we see a substantial increase. Third, after the text messages stop, the savings behavior looks very similar again across groups, and we observe no long-run impact on savings habits.

Also, in contrast to the Peer Group Treatment, the effect of the text messages does not seem to decay over the three treatment months. This might be due to the fact that the default with respect to continuing participation is different: In order to stop participating in the text message service, individuals would have to actively opt out, while for the Peer Group Treatment to continue, participants have to actively opt in each week by attending the meeting. The effect of text messages might therefore be more sustainable over time. Future research is required to test the effectiveness of the messages over the long run.

In order to estimate the significance of the treatment effects, we ran regressions of the following form:

$$
S_{i}=\alpha+\beta_{1} \text { Treatment }_{i}+\text { Prior Savings }_{i}+\epsilon_{i}
$$

where $S_{i}$ is the savings outcome for individual $i$, and Treatment is a dummy variable equal to one for individuals in the treatment groups. In addition, we control for the amount saved prior to the intervention period, which reduces much of the noise by capturing individual-specific variation, similar to what would be the case in a differencein-difference specification. ${ }^{29}$ We use the following measures of $S_{i}$ : (1) total number of deposits, (2) total amount deposited, (3) net new savings (deposits - withdrawals), and (4) average monthly balance. All these outcomes are measured between August and October 2009, the duration of the Feedback Message Experiment. Amounts are also shown winsorized at the top $1 \%$ and $5 \%$ for strictly non-negative variables, and at the top and bottom $1 \%$ and $5 \%$ for other variables.

Table 4 presents the results for all four outcomes during the intervention period. Panel A shows intent-to-treat (ITT) and Panel B treatment-on-the-treated (TOT) effects. ${ }^{30}$ The feedback text messages have a substantial effect on savings. In the ITT

\footnotetext{
${ }^{29}$ Results without controlling for prior balance (shown in Table A6 in the Appendix) are qualitatively similar but measured more imprecisely.

${ }^{30}$ Since the treatments are stratified across groups, clustering standard errors at the group level does
} 
specification, the average number of deposits is almost three times that of the control group, and the amount deposited is 6,000 pesos higher. Overall, participants in the treatment group increase their net new savings in the intervention period by about 7,800 pesos and their average monthly savings balance by about 9,000 pesos. ${ }^{31}$ Take-up rates of the two treatments are very similar. Of participants who initially express interest in the service, $41.4 \%$ end up signing up when offered the Peer Pressure service and $42.5 \%$ when offered the Peer Information service. ${ }^{32}$ Correspondingly, the TOT effects are somewhat more than double in size, increasing amounts deposited 6-fold in the full sample and 3.5fold in the winsorized sample. To put these numbers in perspective, Karlan et al. (2016) find that in a pooled sample from Peru, Bolivia and the Philippines, simple monthly savings reminders increased savings by $6 \%$.

[Table 4 about here.]

With respect to the relationship of the Feedback Message Experiment to the preceding Peer Group Experiment, two questions arise. 1) Is there an interaction effect of having been in the Peer Group Treatment on the effectiveness of the Feedback Message Treatment? 2) How do the magnitudes of the Peer Group and Feedback Message Treatments compare? Given the random assignment in both experiments, we can test the first question directly (see Table A7 in the Appendix). Analysis of the interaction between the treatments in the two experiments shows no significant effect of having been in the Peer Group Treatment on take-up or effectiveness of the Feedback Message Treatments. However, the estimates are not precise and we cannot rule out that the Peer Group Treatment affected the response to the Feedback Message Treatment. ${ }^{33}$ With respect to the second question, comparison of the treatment effects between the two experiments (Peer Group Treatment versus feedback messages) clearly has to be interpreted with much caution,

not affect the results.

${ }^{31}$ The coefficient on prior savings is positive for number of deposits, amount deposited and average monthly balance as participants who saved more before are more likely to save and have higher balances. The coefficient is, however, negative for net new savings since mechanically, people who have prior savings can withdraw more in the intervention period, leading to possible negative new savings.

${ }^{32}$ Take-up was not significantly different for those who had previously received the Peer Group Treatment than for those who had received the basic account (39.0\% vs. $35.4 \%$ respectively). Take-up was highest $(53.5 \%)$ among those in the High-Interest Treatment.

${ }^{33}$ We can also look at how overall prior savings behavior correlates with the treatment effect in the Feedback Message Experiment. Table A8 in the Appendix shows that the Feedback Message Treatments have a larger effect on individuals who had made more prior deposits and deposited higher amounts. It is of course endogenous who saved more prior to the Feedback Message Experiment, so these correlations have to be interpreted with some caution. 
since it is not based on random assignment. The treatment happens in a different year, to a different subsample of participants, and over a different length of time. However, a back-of-the-envelope calculation allows us to get some sense of how much of the effect of the Peer Group Treatment can be achieved without physical meetings.

First, we need to take into account that participants in the Feedback Message Experiment are a non-random subsample of the Peer Group Experiment. We therefore recalculate the effect of the Peer Group Treatment among only those 871 participants. To further increase comparability, we hold the duration constant and focus on the initial period, when the Peer Group Treatment had the strongest effect. This stacks the odds in favor of the Peer Group Treatment, and therefore provides a conservative estimate for the hypothesis that the physical meeting component of the Peer Group Treatment is less important than expected. It also has the advantage of controlling for seasonal effects, since it compares savings in the same calendar months one year apart. Table A9 in the Appendix shows this specification and indicates a treatment effect of 10,275 pesos for the Peer Group Treatment among this sample.

Finally, TOT and ITT for the Peer Group Experiment are by construction identical in this sample, since all participants in the Feedback Message Experiment opened a savings account in the scope of the Peer Group Experiment. For a conservative comparison, we therefore compare it with the ITT effect of the Feedback Message Experiment in Table 4, where savings increase by about 7,800 pesos. ${ }^{34}$ This back-of-the-envelope calculation suggests that feedback text messages can achieve $75 \%$ or more of the effect of the Peer Group Treatment in terms of new savings balance, and implies that physical meetings might not be as central to the effect of the Peer Group Treatment as previously thought.

In sum, feedback text messages provide an alternative delivery mechanism to the Peer Group Treatment that has a substantial effect on savings and is potentially more scalable. They strip the bundle of interventions used in the Peer Group Treatment of many elements and thereby provide a first step towards understanding the underlying mechanisms.

\section{Is Peer Pressure Required for the Effectiveness?}

The previous section established that feedback text messages can achieve substan-

\footnotetext{
${ }^{34}$ If we choose the specification that does not control for prior balance, shown in Table A6, then the benchmark effect of the text messages is even higher, at 10,275 pesos.
} 
tial increases in savings rates without actual in-person meetings like in the Peer Group Treatment. This section investigates whether the effect can also be achieved without peer pressure, by comparing the two types of Feedback Message Treatments (see Section 2 for a description of their design).

Figure 5 shows the ITT effect of the Peer Pressure Treatment compared to both the control group and the Peer Information Treatment. The savings behavior in the two treatments follows a very similar pattern, both in terms of the number of deposits per month (Panel A) and in terms of amount deposited (Panel B).

[Figure 5 about here.]

Table 5 confirms this impression with regressions, showing the results for the two treatments separately. Both treatments independently increase deposits compared to the control group. Net new savings increase significantly for the Peer Information treatment, but not the Peer Pressure treatment. The difference between the two text message treatments is not statistically significant for any of the specifications and outcomes.

[Table 5 about here.]

What we can conclude from this experiment is that feedback text messages can be highly effective even without the Savings Buddy and that peer pressure is not required. The fact that the Peer Pressure and Peer Information Treatment have similar effects suggests that it may be the regular feedback and reminder effect of the messages that is driving the results. However, to test this hypothesis rigorously, further research is required. In particular, it would be interesting to compare the effectiveness of Peer Pressure and Peer Information messages to simple feedback messages and pure reminder messages to disentangle the various potential mechanisms.

The fact that the Peer Pressure Treatment does not lead to stronger effects is even more striking in light of a) the kind of person participants chose as their Savings Buddy and b) the information contained in the Peer Information messages.

a) When signing up for the text message service, participants in the Peer Pressure Treatment indicated their relationship to the Savings Buddy and the main reason they chose that person. Participants were allowed to select their own Savings Buddy so that they could choose their "optimal" peer. The reasons given for choosing that particular 
person indeed indicate that participants are using the text message services as a form of peer pressure and select Savings Buddies who genuinely hold them accountable. The most frequently stated reason $(31 \%)$ is that the person chosen is very strict and will motivate the participants to comply with their savings goal (see Table A10 in the Appendix). This is followed by $29 \%$ indicating that the person was chosen because the participant generally shares financial information with them; $19 \%$ because the person is a role model when it comes to saving, by being very organized and good at complying with his or her own savings goals; and $12 \%$ because the participant shares a bank account with that person. Very few participants (5\%) indicate that they chose their Savings Buddy for being a relaxed person who would be understanding if the participant could not reach their savings goal.

In terms of their relationship to their Savings Buddy, participants tend to choose someone who is close to them, either a close relative or a close friend. The most common choice is a son or daughter (33\%), followed by partner $(25 \%)$, close friend $(17 \%)$, other relative $(14 \%)$, parent $(5 \%)$, neighbor $(2 \%)$, and someone else (3\%). According to Mas and Moretti (2009), peer pressure can be expected to be particularly strong if the peers know each other, have had past interactions, and expect future interaction. Similarly, research by Ferrara (2003) and Karlan (2007) shows that in peer lending groups, close social connections can reduce default. This would suggest that the selected peers should be particularly effective. However, we cannot rule out that in our context, the optimal social distance is different, for example if close peers are too understanding when a goal is not reached and therefore less likely to exert pressure.

b) One possible explanation for why the Peer Pressure Treatment does not have a stronger effect than the Peer Information Treatment could be that the peer pressure effect is strong, but the effect of the information about the performance of others is equally strong. While we cannot rule out that this could be the case, the nature of the information that was conveyed suggests that this is not very likely. The message in the Peer Information Treatment (see text in Appendix A) informs participants about the percentage of others similar to them that made a deposit in a given week. It turns out that in most weeks, that number is very low or even zero. On average, they are informed that $6 \%$ of their peers made a deposit in a given week, and this share ranges from 0 to $20 \%$ depending on the week and their assigned comparison group. This fact, combined with evidence from Beshears et al. (2015) showing that such information may have very limited effects on savings, suggests that the peer information component is not very likely 
to have had a strong effect.

In sum, we find that feedback text messages are effective even without a Savings Buddy and that peer pressure is not required. This is important as peer information text messages are less cumbersome to implement and scale. It also avoids the potential disutility from social pressure, which can make participants potentially worse off (e.g., DellaVigna et al., 2012). In further research, it would be interesting to explore the specific mechanisms driving the effectiveness of the feedback messages.

\section{Benchmarking the Effect of Peer Groups against that of a High Interest Rate}

The results so far show that the Peer Group Treatment can be a powerful tool to increase savings - even if the mechanism might be more due to feedback and follow-up than through peer pressure. We now compare this behavioral intervention to a more traditional incentive to increase savings, an increased interest rate. This section compares the effect of the Peer Group Treatment to the High-Interest Treatment in which the real interest rate was increased to $5 \%$ annually, instead of the $0.3 \%$ in the basic and peer group accounts.

In addition to serving as a benchmark for the Peer Group Treatment, the HighInterest Treatment allows us to test the impact of the interest rate on savings. This setting provides a particularly strong test since, in the context of this experiment, the higher interest rate was made exceptionally salient, including an entire training session that elaborated this point (see Section 2).

While, from a theoretical perspective, an argument could be made that the overall effect of interest rates on savings is ambiguous, due to the income effect that could potentially dominate the substitution effect, ${ }^{35}$ the prediction on the substitution effect is clear: In the absence of significant transaction costs, individuals should reallocate their savings portfolio towards the higher-return account. In our setting, we have the ability not only to look at the overall effect of the interest rate on savings, but also at whether participants who had pre-existing savings move them to the high-interest account. Since the $5 \%$ interest rate is higher than anything else offered in the market for these populations, we

\footnotetext{
${ }^{35}$ In practice, the income effect is likely to be less important for shorter-term precautionary savings, such as those in this study.
} 
expect that their pre-existing savings have a lower return. If the interest rate does not lead to such reallocation of the savings portfolio to the account with the highest return, policies and theories based on the premise that the interest rate is an effective tool to steer savings may have to be called into question to some degree, at least for this type of population.

[Figure 6 about here]

Figure 6 shows the mean monthly savings balance as well as the 75th, 95th, and 99th percentiles. ${ }^{36}$ Looking at the mean, it is not readily apparent whether the savings balance differs between the High-Interest Treatment and either the Peer Group Treatment or the basic account. However, Panels B-D show that looking at the whole distribution reveals a much starker result. The vast majority of participants do not respond to the increased interest rate at all. At the 75 th and even at the 95th percentile, the savings balance in the basic account and the High-Interest Treatment are virtually identical, while participants in the Peer Group Treatment display substantially higher savings. Only at the very top of the distribution (Panel D for the 99th percentile) does the interest rate lead to higher savings. In sum, Figure 6 indicates that the Peer Group Treatment shifts the entire distribution of savings, while the increased interest rate only affects the very top tail of the savings distribution.

The results of Table 3 support those findings in regressions for all three of our savings outcomes. The Peer Group Treatment not only leads to a much bigger increase in the number of deposits than the High-Interest Treatment, but also to a substantially higher balance. The treatment effect on the balance is almost twice as large overall (but measured with substantial noise), and almost eight times larger when we winsorize the top 5\% (measured more precisely). Consistent with the graphical evidence above, the difference is statistically significant in the winsorized specifications but insignificant in the non-winsorized specification. Overall, this suggests that while we cannot draw precise conclusions on the highest amounts, for amounts below the $95^{\text {th }}$ percentile the effects of the interest rate seem to be small. If we take the non-winsorized results from Column (5) and linearly extrapolate the point estimation of the interest rate increase, the results suggest that the Peer Group Treatment has an effect equivalent to an increase in the interest rate of $7.8 \%$.

\footnotetext{
${ }^{36}$ The median is zero, given that take-up is only about $50 \%$.
} 
The fact that an increase in the interest rate of almost five percentage points does not appear to increase savings for most participants is noteworthy. We next investigate whether those participants who had substantial pre-existing savings reallocate them to the higher-yield account. When asked in the follow-up survey, less than $1 \%$ indicate having made any transfers from a pre-existing account into their study account. Since for small amounts of savings, the transaction costs may be too large to warrant reallocation, we also split the group of those with pre-existing accounts further in two, and focus on those with above-median pre-existing balance. Interestingly, even these "high pre-treatment savers" do not shift their savings towards the high-interest account. While their average balance in the pre-existing accounts is about 342,000 pesos (or about 700 USD), their savings in the study accounts are only about 14,000 pesos. ${ }^{37}$

There are many potential explanations: tangible or mental costs associated with this transaction, limited liquidity of the alternative account, a lack of understanding of the interest rate, mental accounting, or reasons other than the interest rate that lead participants to prefer the alternative bank account. Determining the specific reasons goes beyond the scope of this paper. However, we elicited some qualitative information through a series of detailed questions in the follow-up survey about the motives for moving or not moving money from other accounts.

Two aspects stand out in the survey responses: a lack of understanding of the interest rate and mental accounting (Thaler, 1990). Concerning the former, only $5 \%$ of participants indicate knowing the interest rate in their other account. Despite that, $63 \%$ of those in the High-Interest Treatment claim that their other savings account has a higher interest rate which, as discussed above, is highly unlikely. Such a lack of knowledge about the high interest rate in the account is surprising, particularly given that participants were made aware in several ways when the accounts were introduced that the high-interest account offered the highest return in the market. As mentioned above, participants were informed about this high return through a pamphlet that included text and illustrations of a growing piggy bank to emphasize the degree to which compounding increases savings. The pamphlet was tested with a similar population to make sure that it was easy to understand. Additionally, the research manager was present in many of the training sessions and found that the training was executed well.

Despite the explicit training about interest rates upon introduction of the High-

\footnotetext{
${ }^{37}$ Similarly, but less surprisingly, we do not observe a shift for those with below-median pre-existing savings. Their average balance is 34,000 pesos in the pre-existing account and 7,000 in the study account.
} 
Interest Treatment, the illustrative brochure and the name of the high-interest account ("Most Profitable Interest in the Market"), it is still possible that the treatment was not effective in communicating the high interest feature (similarly to the limited effect many financial education programs have in the U.S., as shown by Lusardi and Mitchell, 2014). While there is some suggestive indication that financial literacy interacted with the HighInterest Treatment, ${ }^{38}$ it is also possible that that interest rate does not significantly impact the demand for savings. This would be in line with the results of Karlan and Zinman (2014) who find in a study in the Philippines that savings did not respond significantly to the interest rate of savings accounts, suggesting that the interest rate may not be very important to this type of saving.

When participants are asked directly for their reasons not to transfer money from their other account into the high-interest account, mental accounting stands out. After soliciting information from participants about the characteristics of the two accounts (with respect to the interest rate, distance, withdrawal restrictions, trust in the bank, friendliness of bank staff, and understandability of the account conditions), we asked those who had another account to categorize a list of potential reasons, in terms of their importance for not making any transfers. As seen in Table A11, mental accounting is named as very important by far the most frequently.

In sum, the comparison between the Peer Group Treatment and the High-Interest Treatment suggests that a behavioral intervention is more effective in this setting in that it increases savings for a much larger part of the population than increasing the financial incentives to save. In addition, even participants who have pre-existing formal savings with lower rates of return do not reallocate their savings to the higher-return account, suggesting a very limited role of the interest rate for savings decisions. However, given the substantial level of noise in the non-winsorized null result, this evidence is mostly suggestive.

\footnotetext{
${ }^{38}$ For individuals who either have an above-median score in a financial literacy test (we use three financial literacy questions similar to the ones used in, e.g., Banks and Oldfield, 2007; Gerardi et al., 2013) or above-median education, the High-Interest Treatment leads to statistically significantly higher savings, while for the rest of the sample it does not.
} 


\section{Discussion and Conclusion}

Peer groups are often used as a way to achieve personal goals, but there has been little empirical evidence evaluating their effectiveness and analyzing what aspects of these groups lead to their success. Our findings that the Peer Group Treatment increases the number of deposits 3.7-fold, and almost double the average savings balance after a year, show that the Peer Group Treatment can be a powerful tool to help participants reach an individual but mutually shared goal. Beyond savings, this mechanism is applicable for a wide area of self-control problems.

The Peer Group Treatment may be particularly effective in areas where a small behavior change can generate a large impact. This is for example the case in our context of precautionary savings where the relatively small magnitudes in dollar amounts (about 15 USD) can have large implications for participants' quality of life. The income stream of these populations is not only low, but also highly volatile. Correspondingly, prior to the intervention, many participants expressed the desire to build a buffer stock against economic shocks, and frustration about their inability to do so on their own. This can have large implications since having a small cushion on the side can, for example, make the difference between paying the utility bill or sleeping in the cold during the freezing Chilean winter. $^{39}$ However, in the context of this study, it is unclear whether the treatment is welfare improving for this population since they are saving and borrowing at the same time.

Adding a savings peer group component is especially convenient in contexts where people meet regularly anyway, such as microfinance groups, schools, sports clubs, or churches. The Feedback Message Experiment suggests that even outside of such contexts, savings can be strongly increased through simple feedback messages. While the various aspects of the Peer Group Treatment can be cumbersome to set up and to maintain, text message services require little coordination and do not rely on physical proximity, making them more broadly applicable. Given the astonishing growth rate of cell phone use worldwide, this is a channel that can potentially reach millions of people and may be attractive to a wider and different population than those who are willing to come together for regular meetings.

In addition, the Feedback Message Experiment makes a first step towards disen-

\footnotetext{
${ }^{39}$ In line with this, Kast and Pomeranz (2014) find that after one year, participants in the Peer Group Treatment are significantly less anxious about their financial future.
} 
tangling the mechanism of the Peer Group Treatment. The fact that regular feedback messages increase savings without physical meetings and without a Savings Buddy that observes participants' behavior suggests that other mechanisms are at play.

First, the results may point to the hypothesis that rather than exerting pressure, participants may simply provide a mutual service to regularly hold each other accountable. Just the virtual presence of a peer group combined with feedback regarding savings may provide the motivation to increase savings. Second, the text messages may simply serve as reminders - perhaps limited attention plays a role and weekly reminders work to bring participants' attention to saving. This may function independently of whether participants are provided information about a peer group. Third, habit formation may lead to increased savings. In combination with limited attention, peer groups and feedback messages could start a habit of savings. The fact that saving levels go back to the level of the control group once the text messages stop, however, points to relatively weak habit formation.

This raises at least four additional research questions: 1) How important is the feedback element, and would simple reminders Karlan et al. (2016) have a similar effect? 2) Could other types of Savings Buddies than the ones chosen by the participants (e.g., in terms of social distance, personality traits, etc.) be more effective at holding them accountable? 3) Does the peer information have a motivational effect after all, despite the fact that participants are informed that only few others are making a deposit each week? 4) How generalizable are these findings to other settings?

Beyond the issue of savings, feedback and follow-up through text messages have many potential applications in other areas where people make resolutions but find it difficult to follow through, such as preventive health measures (e.g., for diabetes, exercising, or vaccinations), environmentally-friendly behavior (e.g., saving energy), education (e.g., completing homework, solving math exercises), etc. As these methods find wider application, the question arises to what degree multiple feedback messages crowd out attention, and further research is required to investigate interactions between multiple messages, as well as the effect of feedback messages over a longer time period.

The analysis of the interest rate serves as a benchmark for the effectiveness of the Peer Group Treatment. In addition, the absence of an effect of the interest rate for most participants is of interest by itself. While further research is needed to investigate the interest rate sensitivity of savings in different contexts and for different populations, 
the result suggests that some caution is warranted in the use of policies or economic models that assume large shares of the population will respond to changes in the interest rate. At the same time, it is important to keep in mind that the result of the overall mean response to the increased interest rate is measured with substantial noise in the non-winsorized specification.

Finally, our results speak to a larger point about behavioral interventions versus financial incentives to affect behavior. A growing pattern of evidence shows the importance of social incentives (e.g., Bandiera et al., 2010; Barankay, 2010; Gneezy and Rey-Biel, 2014) and surprisingly limited effects of monetary rewards, even for financial decisions (e.g., Choi et al., 2010; Gneezy et al., 2011; Karlan and Zinman, 2014). Our finding of strong effects of the Peer Group Treatment and suggestive evidence from the feedback messages, compared to the limited effectiveness of the interest rate, fits into this pattern. This is consistent with a new and rapidly growing literature that uses field experiments to directly compare social and behavioral interventions with financial incentives (e.g., Bertrand et al., 2010; Ashraf et al., 2012; Chetty et al., 2013). While traditional economic incentives may be effective in contexts where individuals lack motivation, they may have limited impact if the constraint that impedes the behavior change lies elsewhere. ${ }^{40}$ Implementing behavior change can be challenging, even for motivated individuals - either psychologically, due for example to self-control problems, or practically, due for example to complicated processes. In these situations, policies that facilitate compliance may be more effective than policies that further increase incentives.

\footnotetext{
${ }^{40}$ We thank Brigitte Madrian for helpful discussions, which allowed us to see our findings in this light.
} 


\section{Acknowledgments}

We thank the editor, three referees, Alberto Abadie, Alberto Alesina, Nageeb Ali, John Beshears, Raj Chetty, Shawn Cole, David Cutler, Pascaline Dupas, Nicola FuchsSchuendeln, Edward Glaeser, Jessica Goldberg, Daniel Hojman, Lakshmi Iyer, Sandy Jencks, Dean Karlan, Lawrence Katz, Michael Kremer, David Laibson, Josh Lerner, Dan Levy, Jeffrey Liebman, Stephan Litschig, Brigitte Madrian, Sendhil Mullainathan, Rohini Pande, Alvin Roth, Guy Stuart, Richard Zeckhauser and participants at various seminars and conferences for helpful comments and discussions. We are grateful to Fondo Esperanza, Banco Credichile and Microdatos for outstanding collaboration in the implementation process. This project would not have been possible without the generous support by the following institutions: the Ford Foundation, Banco Credichile, the Lab for Economic Applications and Policy (LEAP) at Harvard, the Women and Public Policy Program at the Harvard Kennedy School, the David Rockefeller Center for Latin American Studies, the Chazen Institute of International Business at Columbia Business School, the Columbia University CIBER, and the Russell Sage Foundation Small Grants Program. 


\section{References}

Allcott, Hunt, "Social Norms and Energy Conservation," Journal of Public Economics, 2011, 95 (9-10), 1082-1095.

Apesteguia, Jose, Patricia Funk, and Nagore Iriberri, "Promoting Rule Compliance in Daily-Life: Evidence from a Randomized Field Experiment in the Public Libraries of Barcelona," European Economic Review, 2013, 64, 266-284.

Ariely, Dan, Anat Bracha, and Stephan Meier, "Doing Good or Doing Well? Image Motivation and Monetary Incentives in Behaving Prosocially.," American Economic Review, 2009, 99 (1), 544-555.

Ashraf, Nava, Dean Karlan, and Wesley Yin, "Deposit Collectors," Advances in Economic Analysis \& Policy, 2006, 6 (2), Article 5.

_ , _ , and _ , "Tying Odysseus to the Mast: Evidence from a Commitment Savings Product in the Philippines," Quarterly Journal of Economics, 2006, 121 (1), 635-672.

_ , _ , and _, "Female Empowerment: Impact of a Commitment Savings Product in the Philippines," World Development, 2010, 38 (3), 333-344.

_ , Oriana Bandiera, and Kelsey Jack, "No Margin, No Mission? A Field Experiment on Incentives for Pro-Social Tasks," Working Paper, 2012.

Ayres, Ian, Sophie Raseman, and Alice Shih, "Evidence from Two Large Field Experiments that Peer Comparison Feedback Can Reduce Residential Energy Usage," Journal of Law, Economics, and Organization, 2012.

Bandiera, Oriana, Iwan Barankay, and Imran Rasul, "Social Incentives in the Workplace," Review of Economic Studies, 2010, 77 (2), 417-458.

Banks, James and Zoe Oldfield, "Understanding Pensions: Cognitive Function, Numerical Ability and Retirement Saving," Fiscal Studies, 2007, 28 (2), 143-170.

Barankay, Iwan, "Rankings and Social Tournaments: Evidence from a Field Experiment," Working Paper, 2010.

Battaglini, Marco, Roland Bénabou, and Jean Tirole, "Self-Control in Peer Groups," Journal of Economic Theory, 2005, 123 (2), 105-134.

Benabou, Roland and Jean Tirole, "Incentives and Prosocial behavior," American Economic Review, 2006, 96 (5), 1652-1678.

Bernheim, Douglas, "A Theory of Conformity," Journal of Political Economy, 1994, 102 (5), 841-877.

Bertrand, Marianne, Dean Karlan, Sendhil Mullainathan, Eldar Shafir, and Jonathan Zinman, "What's Advertising Content Worth? Evidence from a Consumer Credit Marketing Field Experiment," Quarterly Journal of Economics, 2010, 125 (1), 263-305.

Beshears, John, James J. Choi, David Laibson, Brigitte C. Madrian, and Katherine L. Milkman, "The effect of providing peer information on retirement savings decisions," The Journal of Finance, 2015, 70 (3), 1161-1201.

Bishop, John, "Drinking from the Fountain of Knowledge: Student Incentive to Study and Learn - Externalities, Information Problems and Peer Pressure," in E. Hanushek and F. Welch, eds., Handbook of the Economics of Education, Vol. 2, Elsevier, 2006, pp. 909 944.

Brune, Lasse, Xavier Giné, Jessica Goldberg, and Dean Yang, "Commitments to Save: a Field Experiment in Rural Malawi," World Bank Policy Research Working Paper 5748, 2011. 
Bryan, Gharad, Dean Karlan, and Scott Nelson, "Commitment Devices," Annual Review of Economics, 2010, 2 (1).

Burgess, Robin and Rohini Pande, "Can Rural Banks Reduce Poverty? Evidence from the Indian Social Banking Experiment," American Economic Review, 2005, 95 (3), 780-795.

Bursztyn, Leonardo, Florian Ederer, Bruno Ferman, and Noam Yuchtman, "Understanding Peer Effects in Financial Decisions: Evidence from a Field Experiment," NBER Working Paper No. 18241, 2012.

Cadena, Ximena and Antoinette Schoar, "Remembering to Pay? Reminders vs. Financial Incentives for Loan Payments," NBER Working Paper No. 17020, 2011.

_ , _ , Alexandra Cristea, and Heber Delgado-Medrano, "Fighting Procrastination in the Workplace: An Experiment," NBER Working Paper No. 16944, 2011.

Carroll, Gabriel, James Choi, David Laibson, Brigitte Madrian, and Andrew Metrick, "Optimal Defaults and Active Decisions," Quarterly Journal of Economics, 2009, 124 (4), 1639-1674.

Chen, Yan, Maxwell Harper, Joseph Konstan, and Sherry Xin Li, "Social Comparisons and Contributions to Online Communities: A Field Experiment on Movielens," The American Economic Review, 2010, 100 (4), 1358-1398.

Chetty, Raj, John N. Friedman, Soren Leth-Petersen, Torben Heien Nielsen, and Tore Olsen, "Active vs. Passive Decisions and Crowd-Out in Retirement Savings," Working Paper, 2013.

Choi, James, David Laibson, and Brigitte Madrian, "Why Does the Law of One Price Fail? An Experiment on Index Mutual Funds," Review of Financial Studies, 2010, 23 (4), 1405-1432.

DellaVigna, Stefano, John List, and Ulrike Malmendier, "Testing for Altruism and Social Pressure in Charitable Giving," Quarterly Journal of Economics, 2012, 127 (1), 1-56.

Demirgüç-Kunt, Asli, Thorsten Beck, and Patrick Honohan, Finance for All?: Policies and Pitfalls in Expanding Access, Washington, DC: World Bank Publications, 2008.

Duflo, Esther and Emmanuel Saez, "Participation and Investment Decisions in a Retirement Plan: The Influence of Colleagues' Choices," Journal of Public Economics, 2002, 85 (1), 121148.

_ and _ , "The Role of Information and Social Interaction in Retirement Plan Decisions: Evidence from a Randomized Experiment," Quarterly Journal of Economics, 2003, 118 (3), 815-841.

_, William Gale, Jeffrey Liebman, Peter Orszag, and Emmanuel Saez, "Saving Incentives for Low-and Middle-Income Families: Evidence from a Field Experiment with H\&R Block," The Quarterly Journal of Economics, 2006, 121 (4), 1311-1346.

Dupas, Pascaline and Jonathan Robinson, "Savings Constraints and Microenterprise Development: Evidence from a Field Experiment in Kenya," American Economic Journal: Applied Economics, 2013, 5 (1), 163-192.

_ and _ "Why Don't the Poor Save More? Evidence from Health Savings Experiments," American Economic Review, 2013, 103 (4), 1138-71.

Engelhardt, Gary V. and Anil Kumar, "The Elasticity of Intertemporal Substitution: New Evidence from 401 (k) Participation," Economics Letters, 2009, 103 (1), 15-17.

Falk, Armin and Andrea Ichino, "Clean Evidence of Peer Effects," Journal of Labor Economics, 2005, 34 (1), $39-57$. 
Ferrara, Eliana, "Kin Groups and Reciprocity: A Model of Credit Transactions in Ghana," The American Economic Review, 2003, 93 (5), 1730-1751.

Frey, Bruno S. and Stephan Meier, "Social Comparison and Pro-Social Behavior: Testing Conditional Cooperation in a Field Experiment," American Economic Review, 2004, 94, 17171722.

Gelber, Alexander, "How do 401(k)s Affect Saving? Evidence from Changes in 401(k) Eligibility," American Economic Journal: Economic Policy, 2011, 3 (4), 103-122.

Gerardi, Kris, Lorenz Goette, and Stephan Meier, "Numerical Ability Predicts Mortgage Default," Proceedings of the National Academy of Science, 2013, June 24, 2013.

Gerencia de Investigacion Financiera, "Encuesta Financiera de Hogares: Metodologia y Principales Resultados EFH 2008," Report, Banco Central de Chile 2013.

Gneezy, Uri and Pedro Rey-Biel, "On the Relative Efficiency of Performance Pay and Noncontingent Incentives," Journal of the European Economic Association, 2014, 12, 62-72.

_ , Stephan Meier, and Pedro Rey-Biel, "When and Why Incentives (Don't) Work to Modify Behavior," Journal of Economic Perspectives, 2011, 25 (4).

Gugerty, Mary, "You can't Save Alone: Commitment in Rotating Savings and Credit Associations in Kenya," Economic Development and Cultural Change, 2007, 55 (2), 251-282.

Harding, Matthew and Alice Hsiaw, "Goal setting and energy efficiency," Technical Report, Citeseer 2011.

Hsiaw, Alice, "Goal-Setting and Self-Control," Journal of Economic Theory, 2013, 148 (2), 601-626.

Jebb, Susan A., Amy L. Ahern, Ashley D. Olson, Louise M. Aston, Christina Holzapfel, Julia Stoll, Ulrike Amann-Gassner, Annie E. Simpson, Nicholas R. Fuller, Suzanne Pearson et al., "Primary Care Referral to a Commercial Provider for Weight Loss Treatment Versus Standard Care: A Randomized Controlled Trial," The Lancet, 2011, 378 (9801), 1485-1492.

Karlan, Dean, "Social Connections and Group Banking," Economic Journal, 2007, 117 (February), F52-F84.

- and Jonathan Zinman, "Price and Control Elasticities of Demand for Savings," Working Paper, 2014.

_ and Sendhil Mullainathan, "Rigidity in Microfinancing: Can One Size Fit All?," QFinance, 2009.

_ , Margaret McConnell, Sendhil Mullainathan, and Johnathan Zinman, "Getting on the Top of Mind: How Reminders Increase Savings," Management Science, 2016.

Kast, Felipe and Dina Pomeranz, "Saving More to Borrow Less: Evidence from Randomized Access to Formal Savings Accounts in Chile," NBER Working Paper No. 20239, 2014.

Kremer, Michael and Dan Levy, "Peer Effects and Alcohol Use Among College Students," The Journal of Economic Perspectives, 2008, 22 (3), 189-206.

Locke, Edwin and Gary Latham, "New Directions in Goal-Setting Theory," Current Directions in Psychological Science, 2006, 15 (5), 265-268.

Ludwig, Jens, Jeffrey Kling, and Sendhil Mullainathan, "Mechanism Experiments and Policy Evaluations," Journal of Economic Perspectives, 2011, 25 (3), 17-38.

Lusardi, Annamaria and Olivia S. Mitchell, "The Economic Importance of Financial Literacy: Theory and Evidence," Journal of Economic Literature, 2014, 52 (1), 5-44.

Madrian, Brigitte and Dennis Shea, "The Power of Suggestion: Inertia in 401(k) Partici- 
pation and Savings Behavior," Quarterly Journal of Economics, 2001, 116 (4), 1149-1187.

Manoli, Dayanand and Saurabh Bhargava, "Why are Benefits Left on the Table? Assessing the Role of Information, Complexity, and Stigma on Take-up with an IRS Field Experiment," Working Paper, 2011.

Mas, Alexandre and Enrico Moretti, "Peers at Work," The American Economic Review, 2009, 99 (1), 112-145.

Meier, Stephan and Charles Sprenger, "Present-Biased Preferences and Credit Card Borrowing," American Economic Journal: Applied Economics, 2010, 2 (1), 193-210.

Milkman, Katherine, John Beshears, James Choi, David Laibson, and Brigitte Madrian, "Using Implementation Intentions Prompts to Enhance Influenza Vaccination Rates," Proceedings of the National Academy of Sciences, 2011, 108 (26), 10415.

Mills, Gregory, William G. Gale, Rhiannon Patterson, Gary V. Engelhardt, Michael D. Eriksen, and Emil Apostolov, "Effects of Individual Development Accounts on Asset Purchases and Saving Behavior: Evidence from a Controlled Experiment," Journal of Public Economics, 2008, 92 (5), 1509-1530.

Mugerman, Yevgeny, Orly Sade, and Moses Shayo, "Long term savings decisions: Financial reform, peer effects and ethnicity," Journal of Economic Behavior \& Organization, 2014, 106, 235-253.

Prina, Silvia, "Banking the Poor Via Savings Accounts: Evidence from a Field Experiment," Case Western Reserve Working Paper, 2012.

Schaner, Simone, "Intrahousehold Preference Heterogeneity, Commitment, and Strategic Savings: Theory and Evidence from Kenya," Working Paper, 2011.

Schelling, Thomas C., "Self-Command in Practice, in Policy, and in a Theory of Rational Choice," American Economic Review, 1984, 74 (2), 1-11.

Schultz, Wesley., Jessica M. Nolan, Robert B. Cialdini, Noah J. Goldstein, and Vladas Griskevicius, "The Constructive, Destructive, and Reconstructive Power of Social Norms," Psychological Science, 2007, 18 (5), 429-434.

Soman, Dilip and Min Zhao, "The fewer the better: Number of goals and savings behavior," Journal of Marketing Research, 2011, 48 (6), 944-957.

Stango, Victor and Jonathan Zinman, "Limited and Varying Consumer Attention: Evidence from Shocks to the Salience of Bank Overdraft Fees," Federal Reserve Bank of Philadelphia Working Paper 11-17, 2011.

Telyukova, Irina A., "Household Need for Liquidity and the Credit Card Debt Puzzle," The Review of Economic Studies, 2013, 80 (3), 1148-1177.

Thaler, Richard, "Anomalies: Saving, Fungibility, and Mental Accounts," The Journal of Economic Perspectives, 1990, 4 (1), 193-205.

_ and Shlomo Benartzi, "Save More Tomorrow ${ }^{\mathrm{TM}}$ : Using Behavioral Economics to Increase Employee Saving," Journal of Political Economy, 2004, 112 (S1), 164-187.

Walsh, Diana C., Ralph W. Hingson, Daniel M. Merrigan, Suzette M. Levenson, L. Adrienne Cupples, Timothy Heeren, Gerald A. Coffman, Charles A. Becker, Thomas A. Barker, Susan K. Hamilton et al., "A Randomized Trial of Treatment Options for Alcohol-Abusing Workers," New England Journal of Medicine, 1991, 325 (11), $775-782$.

Zinman, Jonathan, "Household Borrowing High and Lending Low Under No-Arbitrage," Working Paper, 2007. 
_ , "Household Debt: Facts, Puzzles, Theories, and Policies," Annual Review of Economics, 2015, 7 (1). 


\section{Figures and Tables}

Figure 1: Peer Group Experiment Design and Timeline

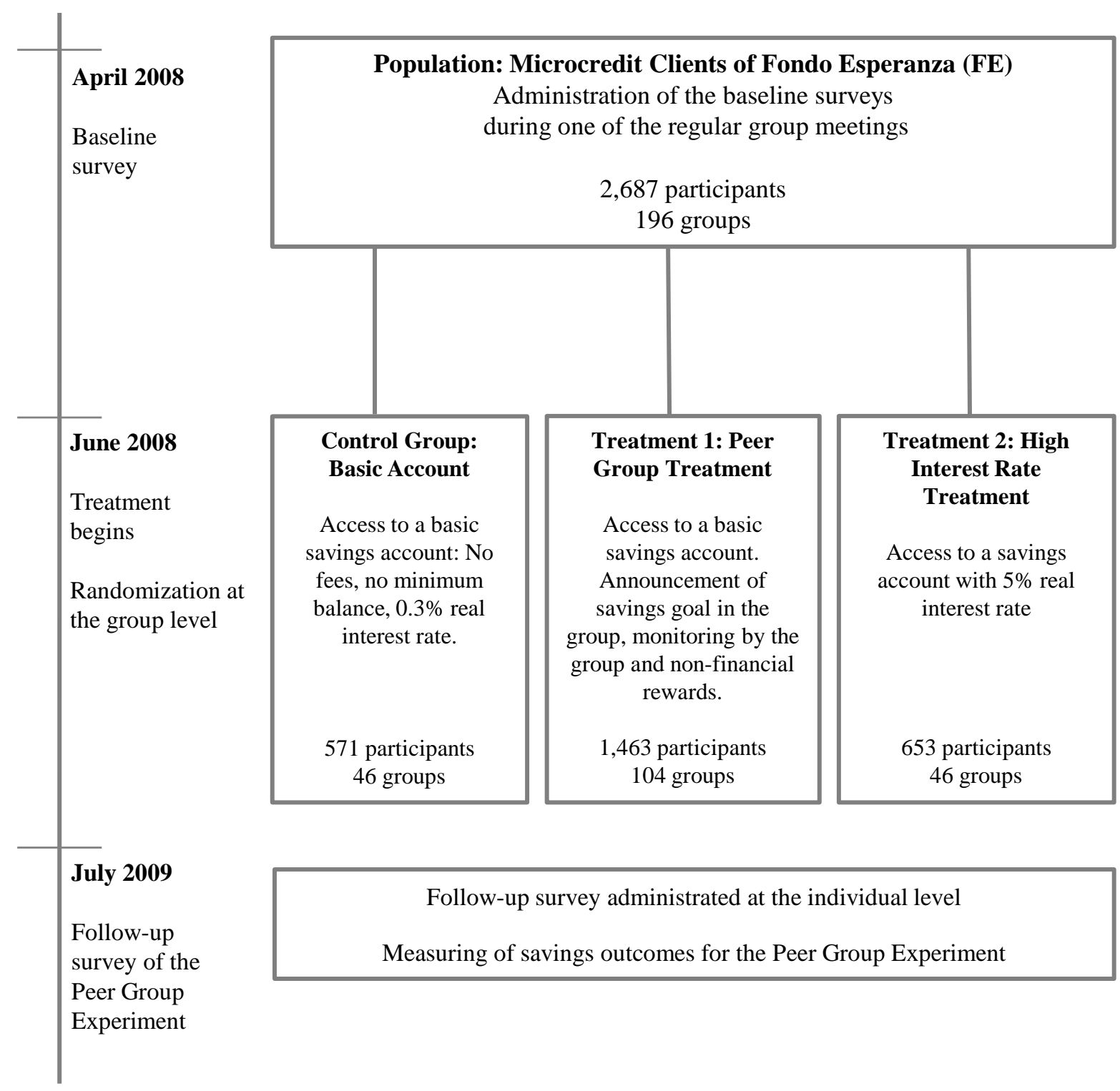


Figure 2: Feedback Message Experiment Design and Timeline

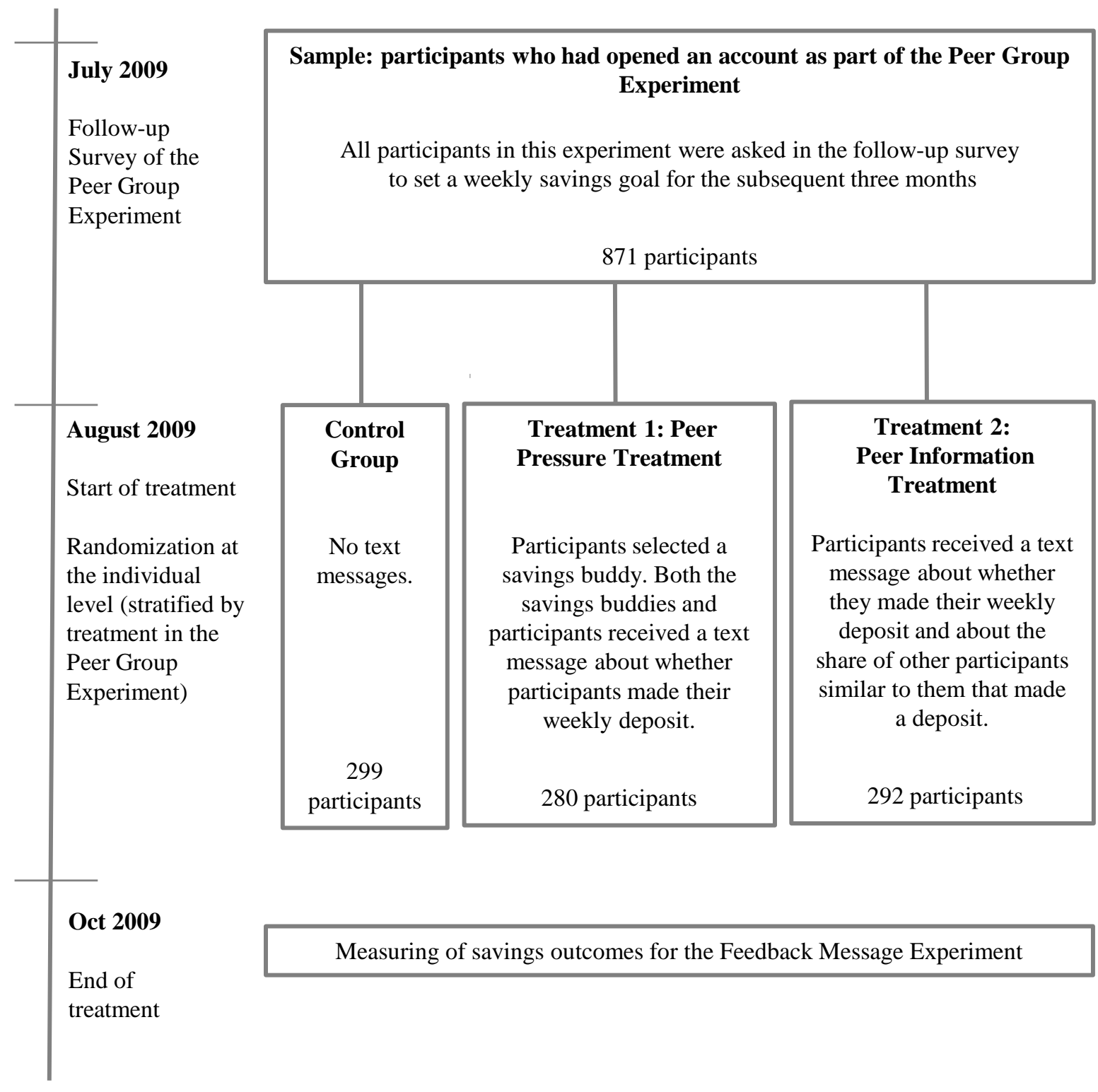



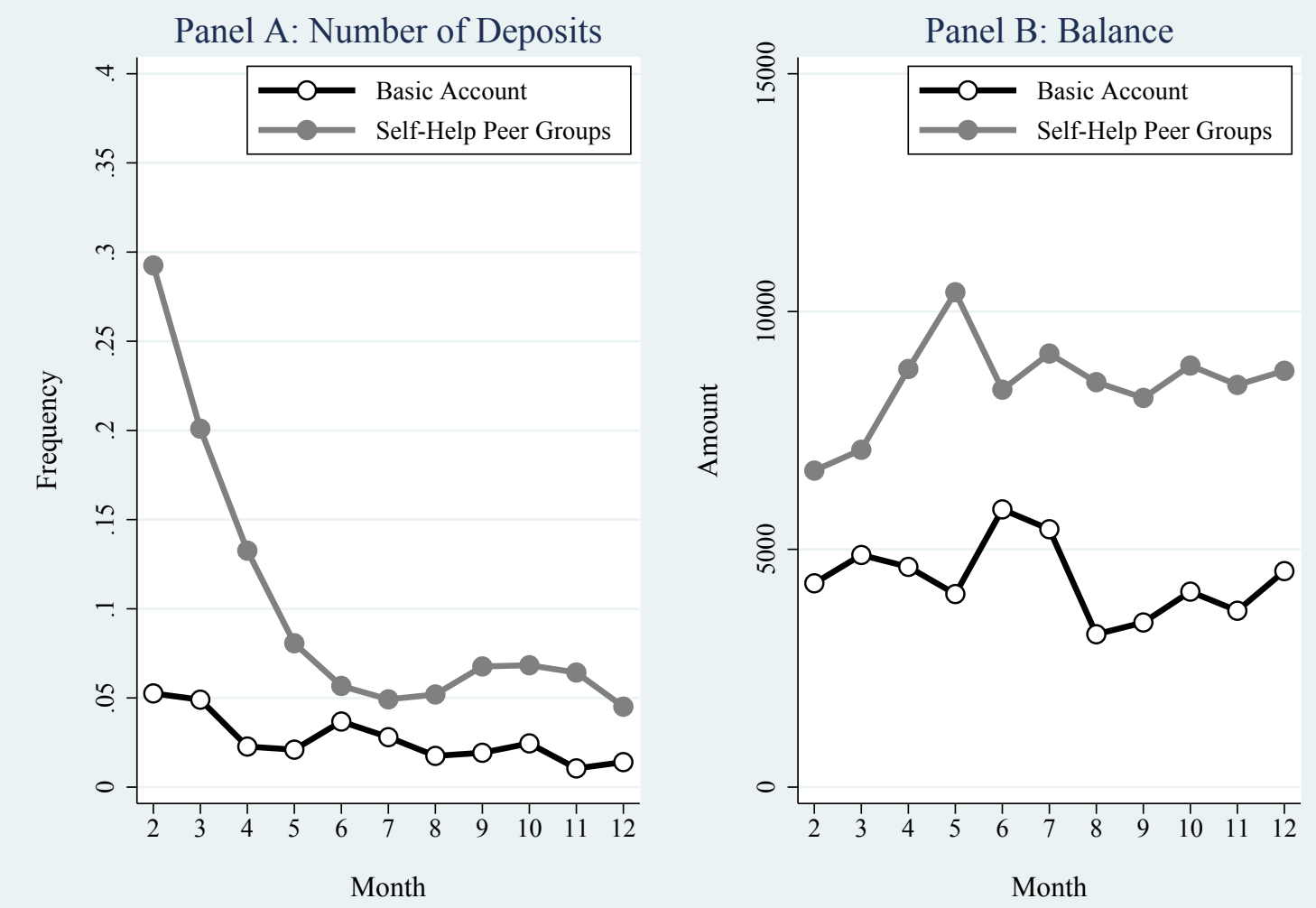

Figure 3: Effect of the Peer Group Treatment on Savings (Experiment 1)

Notes: Panel A shows the number of deposits in a given month. Panel B shows the average balance in the study accounts. "Month" indicates the months since the start of the experiment. All amounts are in Chilean pesos. 500 pesos = approximately 1 USD. 

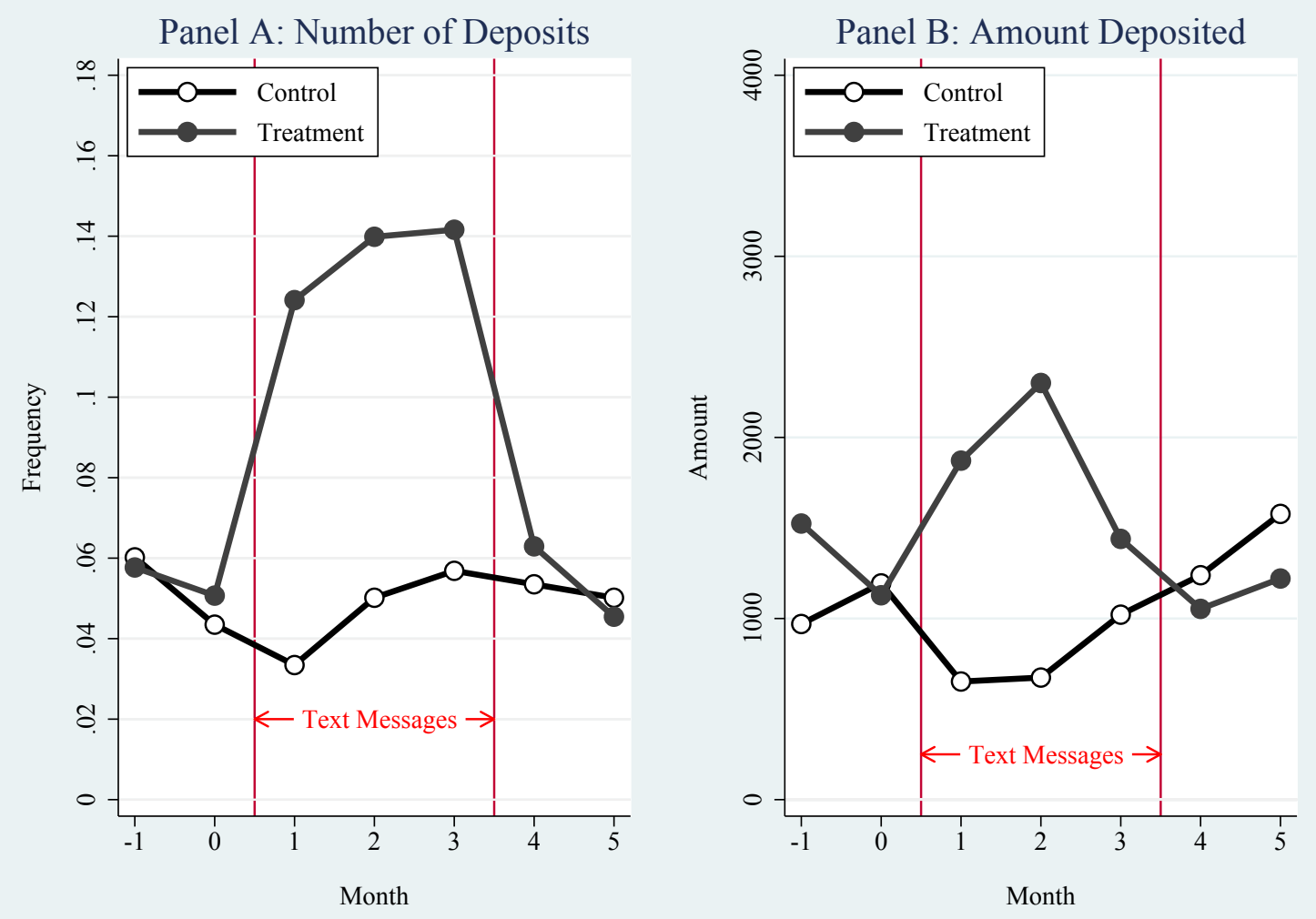

Figure 4: Effect of Feedback Text Messages on Savings (Experiment 2)

Notes: Panel A shows the monthly number of deposits and Panel B the amount deposited, winsorized at the top 5\%. The experiment started in August (month 1) and ended in October 2009 (month 3). All amounts are in Chilean pesos. 500 pesos = approximately 1 USD. 

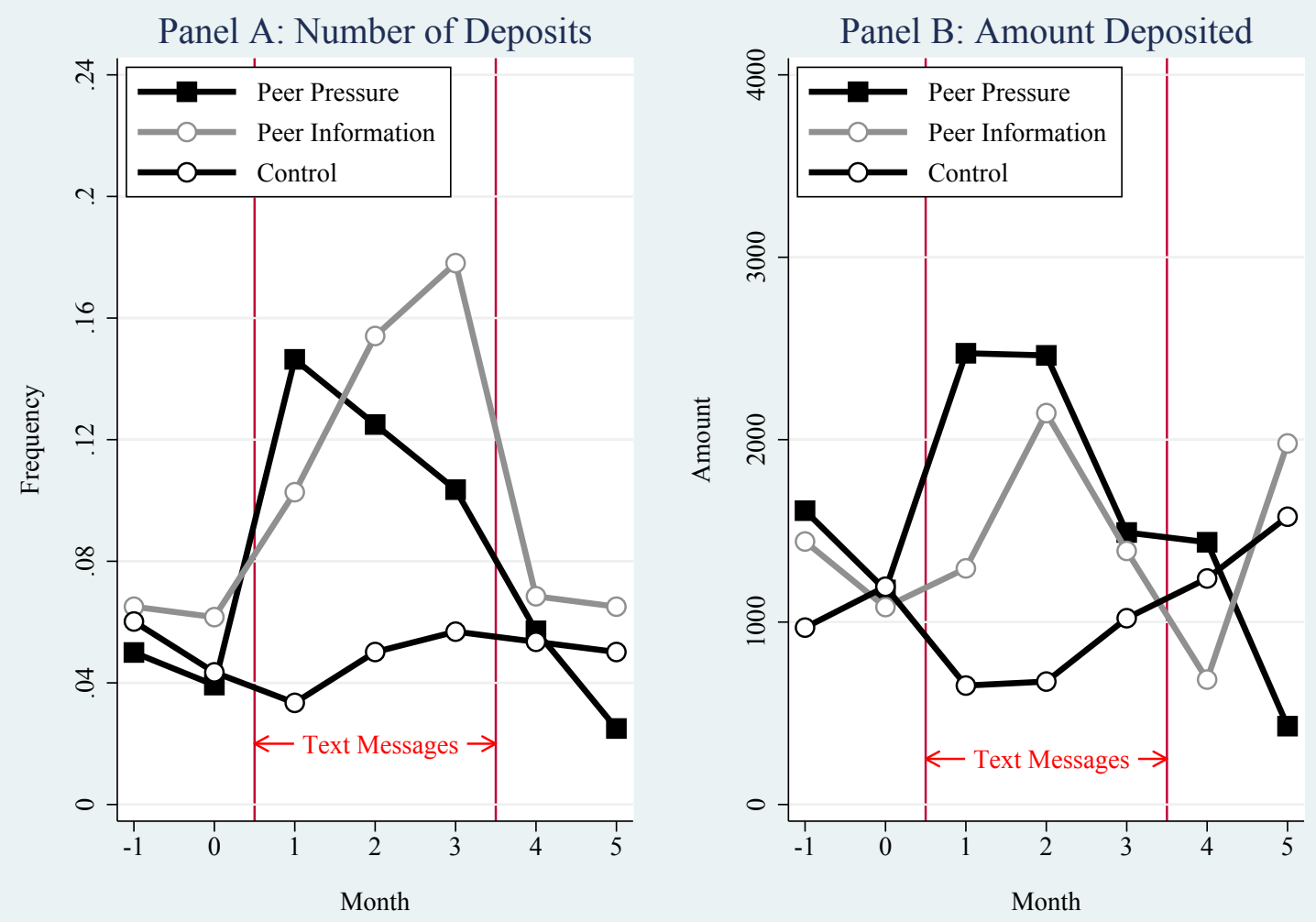

Figure 5: Impact of Peer Pressure through a Savings Buddy (Experiment 2)

Notes: Panel A shows the monthly number of deposits and Panel B the amount deposited, winsorized at the top 5\%. The experiment started in August (month 1) and ended in October 2009 (month 3). All amounts are in Chilean pesos. 500 pesos = approximately 1 USD. 

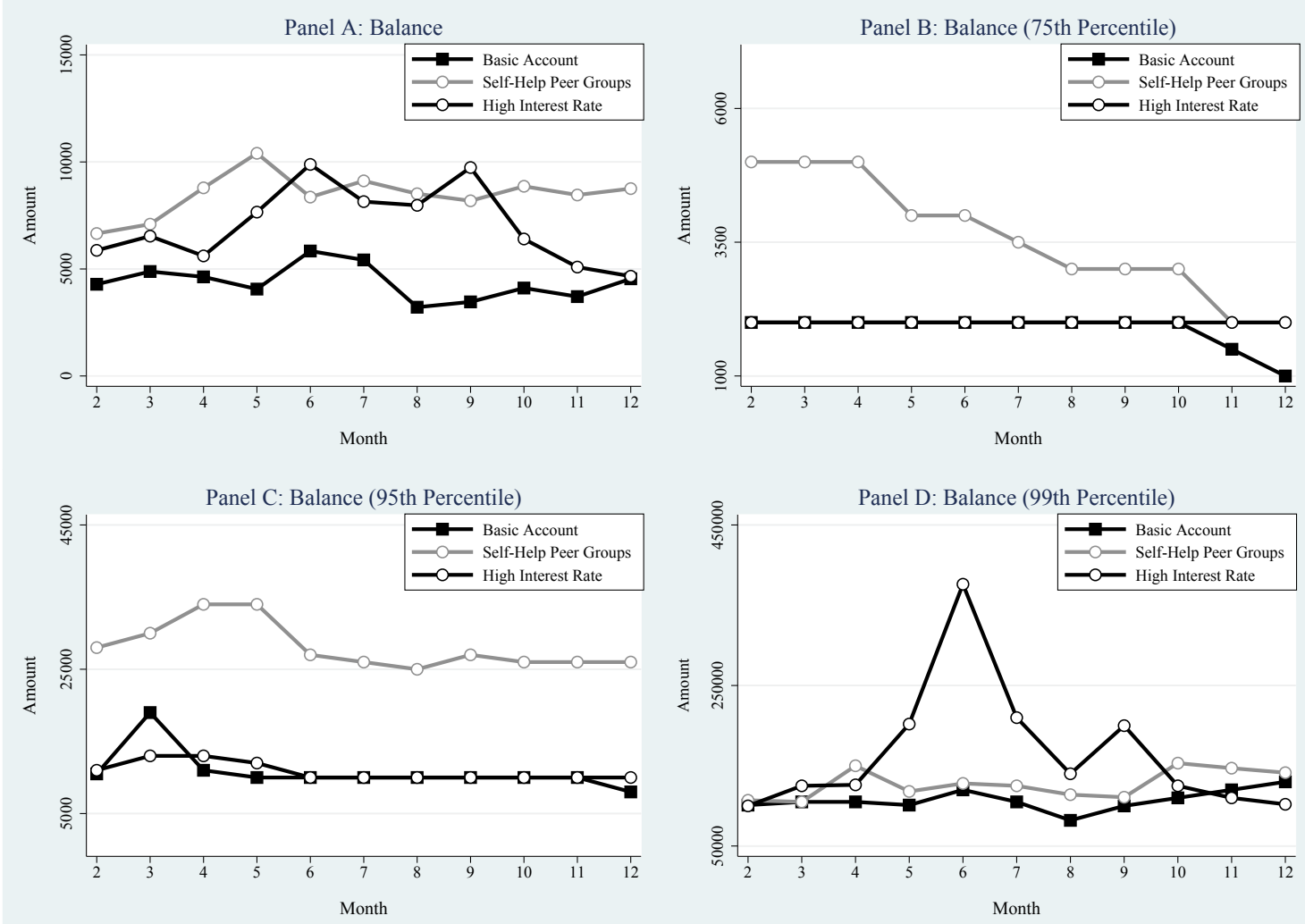

Figure 6: Effect of Peer Group Treatment and High Interest (Experiment 1)

Notes: Panel A shows the average balance in the study accounts. Panels B, C and D show the 75th, 95th and 99th percentile, respectively. "Month" indicates the months since the start of the experiment. All amounts are in Chilean pesos. 500 pesos = approximately 1 USD. 
Table 1: Summary Statistics and Balance of Randomization (Peer Group Experiment)

\begin{tabular}{lcccc}
\hline \hline Variable: & $\begin{array}{c}\text { All } \\
\text { Accounts }\end{array}$ & $\begin{array}{c}\text { Control } \\
(1)\end{array}$ & $\begin{array}{c}\text { Difference Peer } \\
\text { Group and Control }\end{array}$ & $\begin{array}{c}\text { Difference High } \\
\text { Interest and Control } \\
\text { and }\end{array}$ \\
\hline Education & 9.65 & 9.59 & 0.06 & $(4)$ \\
Age & $(3.06)$ & $(3.01)$ & $(0.15)$ & $(0.18)$ \\
Income per capita (monthly) & 43.39 & 43.49 & 0.10 & -0.64 \\
& $(11.58)$ & $(11.70)$ & $(0.57)$ & $(0.66)$ \\
Household size & 80,519 & 80,187 & 335 & 615 \\
& $(58,901)$ & $(55,308)$ & $(2,924)$ & $(3,395)$ \\
Has pre-study savings account & {$[67,375]$} & {$[67,167]$} & {$[1,167]$} & $-1,000]$ \\
& 4.33 & 4.42 & -0.14 & $(0.10)$ \\
Savings balance in other formal accounts & $(1.75)$ & $(1.82)$ & $(0.09)$ & -0.02 \\
& 0.33 & 0.35 & -0.03 & $(0.03)$ \\
Financial debt & $(0.47)$ & $(0.48)$ & $(0.02)$ & $-15,252$ \\
& $(290,380$ & 80,087 & $-13,592$ & $(16,636)$ \\
& {$[0]$} & $(430,749)$ & $(14,328)$ & {$[0]$} \\
Group Size & 287,326 & 464,643 & $-201,953^{*}$ & $-277,172^{* *}$ \\
& $(2,227,464)$ & $(4,557,721)$ & $(109,849)$ & $(127,548)$ \\
\hline Number of Observations & {$[66,000]$} & {$[55,800]$} & {$[15,200]^{* *}$} & {$[7,850]$} \\
\hline \hline
\end{tabular}

Notes: In Columns (1)-(2), standard deviations are presented in parentheses below group means and medians are presented in brackets. Columns (3)-(4) show the difference between treatment and control groups by regressing the variable of interest on treatment dummies. All variables are at baseline in 2008. Robust standard errors clustered at the group level in Columns (3)-(4) are shown in parentheses and medians in brackets. The number of observations varies slightly by variable depending on availability. Monetary figures in Chilean pesos. 500 pesos $=$ approximately 1 USD. Level of significance: ${ }^{*} p<0.1,{ }^{* *} p<0.05,{ }^{* * *} p<0.01$. 
Table 2: Summary Statistics and Balance of Randomization (Feedback Message Experiment)

\begin{tabular}{|c|c|c|c|c|c|}
\hline Variable: & $\begin{array}{c}\text { All } \\
\text { Accounts } \\
(1)\end{array}$ & $\begin{array}{c}\text { Control } \\
(2)\end{array}$ & $\begin{array}{c}\text { Difference Peer } \\
\text { Pressure and Control } \\
(3)\end{array}$ & $\begin{array}{c}\text { Difference Peer } \\
\text { Information and Control } \\
(4)\end{array}$ & $\begin{array}{c}\text { Difference Participants Exp. } 2 \\
\text { and others in Exp. } 1 \\
(5)\end{array}$ \\
\hline \multirow[t]{2}{*}{ Education } & 9.72 & 9.66 & 0.06 & 0.12 & 0.09 \\
\hline & $(3.02)$ & $(3.06)$ & $(0.25)$ & $(0.25)$ & $(0.13)$ \\
\hline \multirow[t]{2}{*}{ Age } & 43.86 & 43.98 & -0.81 & 0.42 & 0.69 \\
\hline & $(10.86)$ & $(10.79)$ & $(0.90)$ & $(0.90)$ & $(0.48)$ \\
\hline \multirow{3}{*}{ Income per capita (monthly) } & 82,636 & 84,506 & $-3,851$ & $-1,893$ & 3,142 \\
\hline & $(69,502)$ & $(92,183)$ & $(5,811)$ & $(5,733)$ & $(2,438)$ \\
\hline & {$[70,000]$} & {$[67,500]$} & {$[2,500]$} & {$[2,500]$} & {$[3,500]^{*}$} \\
\hline \multirow[t]{2}{*}{ Household size } & 4.38 & 4.39 & 0.12 & -0.15 & 0.08 \\
\hline & $(1.69)$ & $(1.58)$ & $(0.14)$ & $(0.14)$ & $(0.07)$ \\
\hline \multirow[t]{2}{*}{ Has pre-study savings account } & 0.34 & 0.30 & $0.07^{*}$ & 0.03 & 0.01 \\
\hline & $(0.47)$ & $(0.46)$ & $(0.04)$ & $(0.04)$ & $(0.02)$ \\
\hline \multirow{3}{*}{ Financial debt } & 240,167 & 231,013 & 25,630 & 2,728 & $-69,777$ \\
\hline & $(578,855)$ & $(580,355)$ & $(48,185)$ & $(47,671)$ & $(91,815)$ \\
\hline & {$[74,856]$} & {$[80,000]$} & {$[-5,824]$} & {$[-1,440]$} & {$[11,856]^{* *}$} \\
\hline \multirow[t]{3}{*}{ Savings balance in study account (Jul 09) } & 12,759 & 14,767 & $-2,520$ & $-3,574$ & $8,830 * * *$ \\
\hline & $(104,377)$ & $(151,918)$ & $(8,689)$ & $(8,597)$ & $(2,753)$ \\
\hline & {$[1,130]$} & {$[2,000]$} & {$[-500]^{* * *}$} & {$[-1,000]^{* * *}$} & {$[1,130]^{* * *}$} \\
\hline Number of prior deposits in study account & 1.52 & 1.49 & -0.02 & 0.08 & $1.10^{* * *}$ \\
\hline (Aug 08-Jul 09) & $(3.82)$ & $(3.86)$ & $(0.32)$ & $(0.31)$ & $(0.11)$ \\
\hline Number of prior withdrawals from study account & 0.70 & 0.69 & -0.02 & 0.05 & $0.48^{* * *}$ \\
\hline (Aug 08-Jul 09) & $(1.49)$ & $(1.41)$ & $(0.12)$ & $(0.12)$ & $(0.06)$ \\
\hline Number of Observations & 871 & 299 & 871 & 871 & 2,687 \\
\hline
\end{tabular}

Notes: In Columns (1)-(2), standard deviations are presented in parentheses below group means and medians are presented in brackets. Columns (3)-(4) show the difference between treatment and control groups, by regressing the variable of interest on treatment dummies. Column (5) shows the difference between the participants included in the Feedback Message Experiment and others in the overall study sample (i.e., those who only participated in the Peer Group Experiment). All variables are at baseline in 2008 unless otherwise indicated. Robust standard errors are shown in parentheses and medians in brackets. The number of observations varies slightly by variable depending on availability. Monetary amounts in Chilean pesos. 500 pesos $=$ approximately 1 USD. Level of significance: ${ }^{*} p<0.1,{ }^{* *} p<0.05,{ }^{* * *} p<0.01$ 
Table 3: The Effect of the Peer Group Treatment on Savings

\begin{tabular}{|c|c|c|c|c|c|c|c|}
\hline & \multirow{2}{*}{$\frac{\# \text { of Deposits }}{(1)}$} & \multicolumn{3}{|c|}{ Amount Deposited } & \multicolumn{3}{|c|}{ Average Monthly Balance } \\
\hline & & $(2)$ & $(3)$ & $(4)$ & $(5)$ & $(6)$ & $(7)$ \\
\hline \multicolumn{8}{|l|}{ Panel A: Intent-to-Treat } \\
\hline Self-Help Peer Groups & $\begin{array}{c}0.836^{* * *} \\
(0.162)\end{array}$ & $\begin{array}{c}14,183^{* * *} \\
(5,363)\end{array}$ & $\begin{array}{c}7,826^{* * *} \\
(2,830)\end{array}$ & $\begin{array}{c}3,286^{* * *} \\
(772)\end{array}$ & $\begin{array}{l}4,050^{* *} \\
(1,888)\end{array}$ & $\begin{array}{c}2,227^{* *} \\
(861)\end{array}$ & $\begin{array}{c}1,817^{* * *} \\
(392)\end{array}$ \\
\hline High-Interest Treatment & $\begin{array}{l}0.0597 \\
(0.104)\end{array}$ & $\begin{array}{l}12,615^{*} \\
(6,964)\end{array}$ & $\begin{array}{c}5,655 \\
(3,642)\end{array}$ & $\begin{array}{c}371 \\
(787)\end{array}$ & $\begin{array}{c}2,446 \\
(1,810)\end{array}$ & $\begin{array}{c}527 \\
(984)\end{array}$ & $\begin{array}{l}232 \\
(368)\end{array}$ \\
\hline Constant & $\begin{array}{c}0.305^{* * *} \\
(0.0710)\end{array}$ & $\begin{array}{c}10,371^{* * * *} \\
(2,552)\end{array}$ & $\begin{array}{c}9,184^{* * *} \\
(1,963)\end{array}$ & $\begin{array}{l}2,960 * * * \\
(528)\end{array}$ & $\begin{array}{c}4,419^{* * *} \\
(930)\end{array}$ & $\begin{array}{c}3,951^{* * *} \\
(673)\end{array}$ & $\begin{array}{c}2,193^{* * *} \\
(269)\end{array}$ \\
\hline $\begin{array}{l}\text { R-squared } \\
\text { F-test "Self-Help" = "High-Interest" }\end{array}$ & $\begin{array}{c}0.022 \\
\mathrm{p}=0.00\end{array}$ & $\begin{array}{c}0.001 \\
\mathrm{p}=0.85\end{array}$ & $\begin{array}{c}0.002 \\
\mathrm{p}=0.56\end{array}$ & $\begin{array}{c}0.012 \\
\mathrm{p}=0.00\end{array}$ & $\begin{array}{c}0.001 \\
\mathrm{p}=0.48\end{array}$ & $\begin{array}{c}0.004 \\
\mathrm{p}=0.06\end{array}$ & $\begin{array}{c}0.017 \\
\mathrm{p}=0.00\end{array}$ \\
\hline \multicolumn{8}{|c|}{ Panel B: Treatment on the (Instrumented) Treated } \\
\hline Self-Help Peer Groups & $\begin{array}{c}1.529^{* * *} \\
(0.277)\end{array}$ & $\begin{array}{c}25,937^{* * *} \\
(9,636)\end{array}$ & $\begin{array}{c}14,312^{* * *} \\
(5,042)\end{array}$ & $\begin{array}{c}6,009 * * * \\
(1,336)\end{array}$ & $\begin{array}{l}7,407^{* *} \\
(3,405)\end{array}$ & $\begin{array}{c}4,073^{* * *} \\
(1,527)\end{array}$ & $\begin{array}{c}3,323^{* * *} \\
(664)\end{array}$ \\
\hline High-Interest Treatment & $\begin{array}{c}0.118 \\
(0.204)\end{array}$ & $\begin{array}{c}24,887^{*} \\
(13,756)\end{array}$ & $\begin{array}{l}11,155 \\
(7,103)\end{array}$ & $\begin{array}{c}732 \\
(1,540)\end{array}$ & $\begin{array}{c}4,826 \\
(3,566)\end{array}$ & $\begin{array}{c}1,040 \\
(1,925)\end{array}$ & $\begin{array}{c}458 \\
(710)\end{array}$ \\
\hline Constant & $\begin{array}{c}0.305^{* * *} \\
(0.0708)\end{array}$ & $\begin{array}{c}10,371^{* * *} \\
(2,544)\end{array}$ & $\begin{array}{c}9,184^{* * *} \\
(1,957)\end{array}$ & $\begin{array}{c}2,960 * * * \\
(526)\end{array}$ & $\begin{array}{c}4,419^{* * *} \\
(928)\end{array}$ & $\begin{array}{c}3,951^{* * *} \\
(671)\end{array}$ & $\begin{array}{c}2,193^{* * * *} \\
(268)\end{array}$ \\
\hline Winsorized & None & None & Top $1 \%$ & Top $5 \%$ & None & Top $1 \%$ & Top $5 \%$ \\
\hline F-test "Self-Help" = "High-Interest" & $\mathrm{p}=0.00$ & $\mathrm{p}=0.95$ & $\mathrm{p}=0.65$ & $\mathrm{p}=0.00$ & $\mathrm{p}=0.54$ & $\mathrm{p}=0.07$ & $\mathrm{p}=0.00$ \\
\hline Number of observations & 2,687 & 2,687 & 2,687 & 2,687 & 2,687 & 2,687 & 2,687 \\
\hline
\end{tabular}

Notes: Dependent variables: Total number of deposits in Column (1); Total amount deposited in Columns (2)-(4); Average balance per month in Columns (5)-(7). All outcomes are for one year after the opening of the accounts and are measured between August 2008 and July 2009. Coefficients of OLS regressions in Panel A and coefficients of two-stage least squares in Panel B. Standard errors clustered at the group level in parentheses. All monetary figures in Chilean pesos. 500 pesos = approximately 1 USD. Level of significance: ${ }^{*} p<0.1,{ }^{* *} p<0.05,{ }^{* * *} p<0.01$ 
Table 4: The Effect of Feedback Text Messages on Savings

\begin{tabular}{|c|c|c|c|c|c|c|c|c|c|c|}
\hline & \multirow{2}{*}{$\frac{\text { \# of Deposits }}{(1)}$} & \multicolumn{3}{|c|}{ Amount Deposited } & \multicolumn{3}{|c|}{ Net New Savings } & \multicolumn{3}{|c|}{ "Average Monthly Balance } \\
\hline & & $(2)$ & (3) & $(4)$ & $(5)$ & (6) & (7) & $(8)$ & (9) & (10) \\
\hline \multicolumn{11}{|c|}{ Panel A: Intent-to-Treat } \\
\hline Assigned to text & $0.268^{* * *}$ & $6,015^{* *}$ & $3,569^{* *}$ & $1,197^{* * *}$ & $7,810^{*}$ & 125 & $339^{*}$ & $8,985^{* *}$ & 2,177 & 669 \\
\hline messages treatment & $(0.0926)$ & $(2,776)$ & $(1,464)$ & $(444)$ & $(4,241)$ & $(1,149)$ & $(184)$ & $(4,156)$ & $(1,373)$ & $(573)$ \\
\hline \multirow[t]{2}{*}{ Prior Balance } & $0.000000962^{* *}$ & $0.135^{* * *}$ & $0.0579 * * *$ & $0.0121^{* * *}$ & $-0.678^{* * *}$ & $-0.0696^{* * *}$ & $-0.00193^{* *}$ & $0.355^{* * *}$ & $0.0962^{* * *}$ & $0.0307^{* * *}$ \\
\hline & $(0.000000421)$ & $(0.0126)$ & $(0.00666)$ & $(0.00202)$ & $(0.0193)$ & $(0.00523)$ & $(0.000839)$ & $(0.0189)$ & $(0.00625)$ & $(0.00261)$ \\
\hline \multirow[t]{2}{*}{ Constant } & $0.126^{*}$ & 826 & 1,670 & $978^{* * *}$ & -200 & -3 & 134 & -842 & $5,162^{* * *}$ & $4,305^{* * *}$ \\
\hline & $(0.0753)$ & $(2,257)$ & $(1,190)$ & $(361)$ & $(3,449)$ & (934) & $(150)$ & $(3,379)$ & $(1,116)$ & $(466)$ \\
\hline R-squared & 0.015 & 0.121 & 0.085 & 0.047 & 0.588 & 0.169 & 0.010 & 0.290 & 0.216 & 0.138 \\
\hline \multicolumn{11}{|c|}{ Panel B: Treatment on the (Instrumented) Treated } \\
\hline Treatment Group & $\begin{array}{c}0.655^{* * *} \\
(0.221)\end{array}$ & $\begin{array}{c}14,693^{* *} \\
(6,743)\end{array}$ & $\begin{array}{c}8,717^{* *} \\
(3,551)\end{array}$ & $\begin{array}{c}2,923^{* * *} \\
(1,068)\end{array}$ & $\begin{array}{l}19,078^{*} \\
(10,390)\end{array}$ & $\begin{array}{c}306 \\
(2,801)\end{array}$ & $\begin{array}{l}828^{*} \\
(445)\end{array}$ & $\begin{array}{c}21,946^{* *} \\
(10,226)\end{array}$ & $\begin{array}{c}5,317 \\
(3,339)\end{array}$ & $\begin{array}{c}1,635 \\
(1,386)\end{array}$ \\
\hline \multirow[t]{2}{*}{ Prior Balance } & $0.000000992^{* *}$ & $0.136^{* * *}$ & $0.0583^{* * *}$ & $0.0122^{* * *}$ & $-0.677^{* * *}$ & $-0.0696^{* * *}$ & $-0.00190^{* *}$ & $0.356^{* * *}$ & $0.0964^{* * *}$ & $0.0307^{* * *}$ \\
\hline & $(0.000000413)$ & $(0.0126)$ & $(0.00662)$ & $(0.00199)$ & $(0.0194)$ & $(0.00522)$ & $(0.000829)$ & $(0.0191)$ & $(0.00623)$ & $(0.00258)$ \\
\hline \multirow[t]{2}{*}{ Constant } & 0.119 & 668 & 1,576 & $947^{* * *}$ & -405 & -6 & 125 & $-1,077$ & $5,105^{* * *}$ & $4,288^{* * *}$ \\
\hline & $(0.0757)$ & $(2,303)$ & $(1,213)$ & $(365)$ & $(3,549)$ & (957) & $(152)$ & $(3,494)$ & $(1,141)$ & $(473)$ \\
\hline Control Group Mean & 0.140 & 2,826 & 2,525 & 1,157 & $-10,211$ & $-1,030$ & 105 & 4,397 & 6,582 & 4,758 \\
\hline Winsorized & None & None & Top $1 \%$ & Top 5\% & None & Top \& Bottom 1\% & Top \& Bottom 5\% & None & Top \& Bottom 1\% & Top \& Bottom 5\% \\
\hline Observations & 871 & 871 & 871 & 871 & 871 & 871 & 871 & 871 & 871 & 871 \\
\hline
\end{tabular}

Notes: All outcomes are measured between August and October 2009, the duration of the Feedback Message Experiment. Net new savings $=($ deposits - withdrawals) during that period. Coefficients of OLS regressions in Panel A and coefficients of two-stage least squares in Panel B. All monetary figures in Chilean pesos. 500 pesos $=$ approximately 1 USD. Level of significance: ${ }^{*} p<0.1$, ${ }^{* *} p<0.05,{ }^{* * *} p<0.01$ 
Table 5: Comparing the Effects of Peer Pressure and Peer Information

\begin{tabular}{|c|c|c|c|c|c|c|c|}
\hline & \multirow{2}{*}{$\frac{\text { \# of Deposits }}{(1)}$} & \multicolumn{3}{|c|}{ בAmount Deposited } & \multicolumn{3}{|c|}{ Net New Savings } \\
\hline & & $(2)$ & $(3)$ & $(4)$ & $(5)$ & (6) & $(7)$ \\
\hline \multirow[t]{2}{*}{ Peer Pressure } & $0.237^{* *}$ & $6,282^{*}$ & $4,366^{* *}$ & $1,311^{* *}$ & 5,844 & -492 & 281 \\
\hline & $(0.108)$ & $(3,236)$ & $(1,706)$ & $(518)$ & $(4,943)$ & $(1,339)$ & $(215)$ \\
\hline \multirow[t]{2}{*}{ Peer Information } & $0.298^{* * *}$ & $5,760^{*}$ & $2,804^{*}$ & $1,087^{* *}$ & $9,696^{* *}$ & 717 & $395^{*}$ \\
\hline & $(0.107)$ & $(3,202)$ & $(1,688)$ & $(512)$ & $(4,891)$ & $(1,325)$ & $(213)$ \\
\hline \multirow[t]{2}{*}{ Prior Balance } & $0.000000963^{* *}$ & $0.135^{* * *}$ & $0.0579 * * *$ & $0.0121^{* * *}$ & $-0.678^{* * *}$ & $-0.0696^{* * *}$ & $-0.00193^{* *}$ \\
\hline & $(0.000000422)$ & $(0.0126)$ & $(0.00666)$ & $(0.00202)$ & $(0.0193)$ & $(0.00523)$ & $(0.000840)$ \\
\hline \multirow[t]{2}{*}{ Constant } & $0.126^{*}$ & 826 & 1,670 & $979 * * *$ & -201 & -3 & 134 \\
\hline & $(0.0753)$ & $(2,258)$ & $(1,191)$ & $(361)$ & $(3,449)$ & $(935)$ & $(150)$ \\
\hline Winsorized & None & None & Top $1 \%$ & Top 5\% & None & Top \& Bottom 1\% & Top \& Bottom 5\% \\
\hline R-squared & 0.016 & 0.121 & 0.086 & 0.047 & 0.588 & 0.170 & 0.010 \\
\hline F-test "Pressure" = "Information" & $\mathrm{p}=0.575$ & $\mathrm{p}=0.872$ & $\mathrm{p}=0.363$ & $\mathrm{p}=0.667$ & $\mathrm{p}=0.439$ & $\mathrm{p}=0.370$ & $\mathrm{p}=0.598$ \\
\hline Number of Observations & 871 & 871 & 871 & 871 & 871 & 871 & 871 \\
\hline
\end{tabular}

Notes: All outcomes are measured between August and October 2009, the duration of the Feedback Message Experiment. Net new savings $=($ deposits withdrawals) during that period. All monetary figures in Chilean pesos. 500 pesos $=$ approximately 1 USD. Level of significance: ${ }^{*} p<0.1,{ }^{* *} p<0.05$, $* * * p<0.01$ 


\section{APPENDIX FOR ONLINE PUBLICATION}

\section{A Text messages (English Translation)}

\section{Peer Pressure Treatment}

- Messages to participants:

- In case of deposit "Congratulations! Last week you made your weekly deposit and we just informed your Savings Buddy of your achievement."

- In case of failure to deposit "Ooh! Last week you did not achieve your weekly deposit and we just informed your Savings Buddy."

- Messages to Savings Buddy:

- In case of deposit by the participant "Good news, last week [NAME OF PARTICIPANT] made his/her weekly deposit. Thanks for being his/her Savings Buddy!"

- In case of failure to deposit "Unfortunately last week [NAME OF PARTICIPANT] did not make his/her weekly deposit. Thanks for being his/her Savings Buddy!"

\section{Peer Information Treatment}

- In case of deposit

"Congratulations! Last week you made your weekly deposit. [PERCENT OF OTHERS]\% of other participants similar to you made a deposit."

- In case of failure to deposit

"Ooh! Last week you did not achieve your weekly deposit. [PERCENT OF OTHERS]\% of other participants similar to you made a deposit." 


\section{B Screening Questions \& Setting of Savings Goal}

During the follow-up survey, all participants who had opened a saving account during the Peer Group Experiment were asked the following questions (English translation):

(1) Do you send or receive text messages on your cell phone from time to time? If response is no because the participant does not have a cell phone, the participant is excluded from the Feedback Message Experiment.

(2) Do your relatives or friends send or receive text messages through their cell phones from time to time?

There is a new service that is incorporating the benefits of mobile technology to help people achieve their savings goals. Many feel that a weekly reminder of their personal savings goals will help them achieve their savings plans.

Therefore, the new service gives people the option of receiving a weekly text message on their cell phones reminding them of their savings goals, and motivating them to achieve them. This helps people achieve the level of savings they desire and to follow their original plan.

(3) Do you believe it is a good idea to offer this service for free to those who have a Fondo Esperanza savings account?

(4) If such a service existed, and you were offered the opportunity to participate completely free, would you like to participate and receive text messages to support you in achieving your savings goals? If response is no, the participant is excluded from the Feedback Message Experiment.

(5) If such a service was offered, for what purpose would you like to save in the next 3 months?

(6) How much money do you want to save weekly over the next three months to achieve this goal? 


\section{Additional Tables}

Table A1: Intensity of Elements of Peers Group Treatment

\begin{tabular}{|c|c|c|c|c|c|}
\hline & $\begin{array}{c}(1) \\
\text { Percent who } \\
\text { responded a) }\end{array}$ & $\begin{array}{c}(2) \\
\text { Percent who } \\
\text { responded b) }\end{array}$ & $\begin{array}{c}(3) \\
\text { Percent who } \\
\text { responded c) }\end{array}$ & $\begin{array}{c}(4) \\
\text { Percent who } \\
\text { responded d) }\end{array}$ & $\begin{array}{c}(5) \\
\text { Percent No Answer } \\
\text { or Don't know }\end{array}$ \\
\hline Frequency of group leader motivating to save & 50.4 & 21.9 & 18.7 & 4.3 & 4.7 \\
\hline Frequency of sticker distribution & 23.0 & 14.6 & 25.2 & 15.0 & 22.2 \\
\hline Frequency of using tracking form & 52.0 & 10.8 & 13.6 & 7.0 & 16.6 \\
\hline Frequency of giving stickers in absence of a deposit slip & 4.6 & 4.2 & 4.0 & 82.1 & 5.1 \\
\hline Were awards given? & 47.9 & 29.0 & $\mathrm{~N} / \mathrm{A}$ & $\mathrm{N} / \mathrm{A}$ & 23.1 \\
\hline
\end{tabular}

Notes: This table provides summary statistics of answers to the following questions from the follow-up survey: 1) "With what frequency did the group leader motivate the group to save in the FE accounts?", 2) "With what frequency did the group leader distribute stickers when participants met their weekly savings goal?", 3) "With what frequency did the group leader use the tracking form?", 4) "Have members of the group received stickers without showing their deposit slip?", and 5) "Was an award given to participants who met their savings goal?". The possible answers for the first three questions were: "Every meeting" = a, "In the majority of the meetings" = b, "Once in a while" = c, "In none of the meetings" = d. The possible answers for the fourth question were: "Many times" $=\mathrm{a}$, "2-3 times" = b, "Once" = c, and "Never" = d. Finally, the possible answers to the last question were: "Yes" = a, "No" = b. "Don't know" or no answer recorded as missing. 
Table A2: Time Inconsistencies (Peer Group Experiment)

\begin{tabular}{|c|c|c|c|c|c|c|}
\hline & \multicolumn{2}{|c|}{ \# of Deposits } & \multicolumn{4}{|c|}{ Average Monthly Balance } \\
\hline & (1) & $(2)$ & $(3)$ & $(4)$ & $(5)$ & $(6)$ \\
\hline \multirow[t]{2}{*}{ Time Inconsistent ${ }^{a} \times$ Self Help } & $0.572^{* *}$ & $0.574^{*}$ & 654 & 644 & 2,627 & 2,489 \\
\hline & $(0.290)$ & $(0.300)$ & $(3,028)$ & $(2,921)$ & $(1,595)$ & $(1,612)$ \\
\hline \multirow[t]{2}{*}{ Time Inconsistent ${ }^{a} \times$ High-Interest } & $0.322^{*}$ & $0.331^{*}$ & 3,942 & $5,468^{*}$ & $2,836^{*}$ & $3,042^{*}$ \\
\hline & $(0.194)$ & $(0.192)$ & $(3,374)$ & $(3,300)$ & $(1,707)$ & $(1,811)$ \\
\hline \multirow[t]{2}{*}{ Time Inconsistent } & -0.0100 & -0.00191 & $-2,100$ & $-1,716$ & $-1,454$ & $-1,078$ \\
\hline & $(0.114)$ & $(0.113)$ & $(1,398)$ & $(1,410)$ & $(1,141)$ & $(1,163)$ \\
\hline \multirow[t]{2}{*}{ Self-Help Peer Groups } & $0.654^{* * *}$ & -0.790 & 3,930 & $-12,164$ & 1,452 & $-9,339^{*}$ \\
\hline & $(0.157)$ & $(0.797)$ & $(2,653)$ & $(8,430)$ & $(1,014)$ & $(5,142)$ \\
\hline \multirow[t]{2}{*}{ High-Interest Treatment } & -0.0516 & -0.0271 & 1,225 & $-5,830$ & -356 & $-3,403$ \\
\hline & $(0.0996)$ & $(0.568)$ & $(2,193)$ & $(11,374)$ & $(1,125)$ & $(7,415)$ \\
\hline \multirow[t]{2}{*}{ Constant } & $0.308^{* * *}$ & $1.081^{* *}$ & $5,000^{* * *}$ & $15,007^{* *}$ & $4,353^{* * *}$ & $10,771^{* * *}$ \\
\hline & $(0.0748)$ & $(0.522)$ & $(1,189)$ & $(6,094)$ & $(810)$ & $(4,082)$ \\
\hline Control variables (and interactions) & No & Yes & No & Yes & No & Yes \\
\hline Winsorized & None & None & None & None & Top $1 \%$ & Top $1 \%$ \\
\hline R-squared & 0.027 & 0.037 & 0.001 & 0.010 & 0.005 & 0.023 \\
\hline Number of Observations & 2,687 & 2,623 & 2,687 & 2,623 & 2,687 & 2,623 \\
\hline
\end{tabular}

Notes: Dependent variables: Total number of deposits in Columns (1) and (2); Total amount deposited in Columns (3) - (6). Control variables (fully interacted with the treatment dummies) are: education, age, household size, initial household income, financial debt, last recorded amount of credit with FE, and bank savings. Controls are demeaned so that the constant term corresponds to the control group mean. All outcomes are measured between August 2008 and July 2009. Standard errors clustered at the group level in parentheses. All monetary figures in Chilean pesos. 500 pesos $=$ approximately 1 USD. Level of significance: ${ }^{*} p<0.1$, ${ }^{* *} p<0.05,{ }^{* * *} p<0.01$

${ }^{a}$ Time inconsistency is measured by giving survey participants choices between $x$ pesos in time $t$ and $y$ pesos $(x<y)$ in time $t+1$ month (similar to e.g., Ashraf et al., 2006b; Meier and Sprenger, 2010). Individuals make those choices for $t=$ today and $t=$ six months from today, which allows us to categorize individuals as being time inconsistent, i.e. present-biased, if they are more impatient when $t=$ today than when $t=6$ months. Using this definition (in which we use the first switching point to determine preferences), about 30\% of participants are classified as time inconsistent. 
Table A3: Effects of Peer Group and High-Interest Treatments on Self-Reported Savings

\begin{tabular}{lccccc}
\hline \hline & $(1)$ & $(2)$ & $(3)$ & $(4)$ & $(5)$ \\
& Deposit & Withdrawal & Amount & Amount & Amount \\
\hline Panel A: Formal Savings & & & & \\
Self-Help Peer Groups & 0.0319 & 0.0313 & 5,323 & 7,338 & 7,360 \\
& $(0.0500)$ & $(0.0398)$ & $(7,991)$ & $(6,814)$ & $(5,945)$ \\
High-Interest Groups & -0.0216 & 0.00968 & 20,705 & $14,746^{*}$ & $13,124^{*}$ \\
& $(0.0491)$ & $(0.0463)$ & $(12,642)$ & $(8,202)$ & $(7,045)$ \\
Constant & $0.356^{* * *}$ & $0.241^{* * *}$ & $60,540^{* * *}$ & $57,011^{* * *}$ & $51,322^{* * *}$ \\
& $(0.0416)$ & $(0.0331)$ & $(6,817)$ & $(5,538)$ & $(4,827)$ \\
\hline R-squared & 0.002 & 0.001 & 0.002 & 0.001 & 0.002 \\
\hline Panel B: All Savings & & & & & \\
Self-Help Peer Groups & & & $-2,250$ & -225 & 1,736 \\
& & & $(16,036)$ & $(14,671)$ & $(12,767)$ \\
High-Interest Groups & & & $(19,112)$ & $(16,312)$ & $(14,427)$ \\
& & & $155,644^{* * *}$ & $150,070^{* * *}$ & $137,361^{* * *}$ \\
Constant & & & $(13,882)$ & $(12,583)$ & $(10,956)$ \\
\hline R-squared & & 0.001 & 0.001 & 0.002 \\
Winsorized & & None & Top 1\% & Top 5\% \\
Observations & 882 & 2,687 & 2,687 & 2,687 \\
\hline \hline
\end{tabular}

Notes: Dependent variables in Columns (1) and (2): dummy variable that is 1 if, in the last 6 months, depositing (Column 1) or withdrew (Column 2) money in another bank account or housing account, and 0 otherwise. Dependent variables: "Formal savings" in Columns (3)-(5) includes self-reported savings amounts in the Fondo Esperanza account, as well as in another bank, a housing account or a cooperative. "All savings" in Columns (3)-(5) includes all formal savings listed above as well as self-reported amount saved at home or in the business, in a ROSCA, with another person, in advanced payments, and an "other" category. If individuals indicated that they had savings in a particular account, e.g. in a ROSCA, but left the amount blank, we imputed the median value. OLS estimates with standard errors clustered at the group level in parentheses. All outcomes are from the 2009 follow-up survey. Values in Chilean pesos. 500 Chilean pesos $=$ approximately 1 USD. Level of significance: ${ }^{*} p<0.1,{ }^{* *} p<0.05$, $* * * p<0.01$ 
Table A4: Effects of Peer Group and High-Interest Treatments on Components of Self-Reported Savings

\begin{tabular}{|c|c|c|c|c|c|c|c|c|c|}
\hline & $\begin{array}{c}(1) \\
\text { Another Bank }\end{array}$ & $\begin{array}{c}(2) \\
\text { Home or Business }\end{array}$ & $\begin{array}{c}(3) \\
\text { Cooperative }\end{array}$ & $\begin{array}{c}(4) \\
\text { ROSCA }\end{array}$ & $\begin{array}{c}(5) \\
\text { Other Person }\end{array}$ & $\begin{array}{c}(6) \\
\text { Advanced Purchase }\end{array}$ & $\begin{array}{c}(7) \\
\text { Other }\end{array}$ & $\begin{array}{c}\text { (8) } \\
\text { FE Account }\end{array}$ & $\begin{array}{c}(9) \\
\text { Housing Account }\end{array}$ \\
\hline Self-Help Peer Groups & $\begin{array}{c}122 \\
(5,332)\end{array}$ & $\begin{array}{l}-6,680 \\
(6,852)\end{array}$ & $\begin{array}{c}777 \\
(1,658)\end{array}$ & $\begin{array}{c}533 \\
(4,086)\end{array}$ & $\begin{array}{c}1,342 \\
(1,194)\end{array}$ & $\begin{array}{l}-5,532 \\
(7,530)\end{array}$ & $\begin{array}{l}-172 \\
(779)\end{array}$ & $\begin{array}{c}4,968^{* * *} \\
(1,845)\end{array}$ & $\begin{array}{c}-536 \\
(6,191)\end{array}$ \\
\hline High-Interest Treatment & $\begin{array}{c}4,038 \\
(6,531)\end{array}$ & $\begin{array}{l}-3,050 \\
(7,090)\end{array}$ & $\begin{array}{c}-505 \\
(1,575)\end{array}$ & $\begin{array}{c}5,998 \\
(5,033)\end{array}$ & $\begin{array}{c}720 \\
(1.200)\end{array}$ & $\begin{array}{r}-10,180 \\
(8,237)\end{array}$ & $\begin{array}{c}1,862 \\
(1,571)\end{array}$ & $\begin{array}{c}1,618 \\
(1,960)\end{array}$ & $\begin{array}{c}15,954 \\
(12,108)\end{array}$ \\
\hline Constant & $\begin{array}{c}22,290 * * * \\
(4,658)\end{array}$ & $\begin{array}{c}46,478^{* * *} \\
(6,081)\end{array}$ & $\begin{array}{l}2,522^{*} \\
(1,306)\end{array}$ & $\begin{array}{l}8,859^{* *} \\
(3,564)\end{array}$ & $\begin{array}{c}2,794^{* * *} \\
(849)\end{array}$ & $\begin{array}{c}54,376^{* * *} \\
(6,677)\end{array}$ & $\begin{array}{c}1,610^{* *} \\
(620)\end{array}$ & $\begin{array}{c}5,598^{* * *} \\
(1,054)\end{array}$ & $\begin{array}{c}42,218^{* * *} \\
(4,959)\end{array}$ \\
\hline$\overline{R \text {-squared }}$ & 0.000 & 0.001 & 0.000 & 0.002 & 0.000 & 0.001 & 0.002 & 0.002 & 0.002 \\
\hline Observations & 2,278 & 2,278 & 2,277 & 2,277 & 2,277 & 2,278 & 2,275 & 2,278 & 2,278 \\
\hline
\end{tabular}

Notes: Dependent variables: amounts of different types of savings. If individuals indicated that they had savings of a particular type, but left the amount missing, we imputed the median value. All outcomes are from the 2009 follow-up survey. Values in Chilean pesos. 500 Chilean pesos $=$ approximately 1 USD. Level of significance: ${ }^{*} p<0.1,{ }^{* *} p<0.05,{ }^{* * *} p<0.01$ 
Table A5: Effects of Peer Group and High-Interest Treatments on Borrowing

\begin{tabular}{lccc}
\hline \hline & $\begin{array}{c}(1) \\
\text { Probability of } \\
\text { FE Borrowing }\end{array}$ & $\begin{array}{c}(2) \\
\text { Probability of } \\
\text { short-term borrowing }\end{array}$ & $\begin{array}{c}(3) \\
\text { Probability of } \\
\text { long-term borrowing }\end{array}$ \\
\hline Self-Help Peer Groups $\times$ Post & -0.0399 & 0.00673 & -0.0225 \\
High-Interest Treatment $\times$ Post & $(0.0578)$ & $(0.0422)$ & $(0.0291)$ \\
& -0.0213 & 0.0573 & -0.00281 \\
Post & $(0.0741)$ & $(0.0435)$ & $(0.0321)$ \\
& $-0.237^{* * *}$ & $-0.595^{* * *}$ & $-0.0945^{* * *}$ \\
Constant & $(0.0462)$ & $(0.0340)$ & $(0.0234)$ \\
& $0.775^{* * *}$ & $0.897^{* * *}$ & $0.799^{* * *}$ \\
R-squared & $(0.0118)$ & $(0.00768)$ & $0.00549)$ \\
F-test "Self-Help" = "High-Interest" & 0.148 & 0.539 & 0.042 \\
Observations & 0.783 & 0.172 & 0.482 \\
\hline \hline
\end{tabular}

Notes: Dependent variables are dummies that take on the value of 1 if the household reports in the baseline and follow-up survey having debt from the following source: Fondo Esperanza in Column (1), short-term debt (owing to family, services, and institutions including cooperatives, moneylenders, goods suppliers, business partners, and store credit) in Column (2) and other long-term debt (bank loans, mortgages, and IOUs) in Column (3). Regressions include baseline and follow-up data with individual fixed effects. Standard errors clustered at the group level in parenthesis. Values in Chilean pesos. 500 Chilean pesos $=$ approximately 1 USD. Level of significance: ${ }^{*} p<0.1,{ }^{* *} p<0.05,{ }^{* * *} p<0.01$ 
Table A6: The Effect of Feedback Text Messages on Savings (Without Controlling for "Prior Balance")

\begin{tabular}{|c|c|c|c|c|c|c|c|}
\hline & \multirow{2}{*}{$\frac{\text { \# of Deposits }}{(1)}$} & \multicolumn{3}{|c|}{ Amount Deposited } & \multicolumn{3}{|c|}{ Net New Savings } \\
\hline & & $(2)$ & $(3)$ & $(4)$ & $(5)$ & $(6)$ & $(7)$ \\
\hline \multicolumn{8}{|c|}{ Panel A: Intent-to-Treat } \\
\hline Assigned to text & $0.265^{* * *}$ & $5,601^{*}$ & $3,392^{* *}$ & $1,160 * *$ & 9,883 & 338 & $345^{*}$ \\
\hline messages treatment & $(0.0928)$ & $(2,952)$ & $(1,525)$ & $(453)$ & $(6,594)$ & $(1,260)$ & $(185)$ \\
\hline \multirow[t]{2}{*}{ Constant } & $0.140^{*}$ & 2,826 & $2,525^{* *}$ & $1,157^{* * *}$ & $-10,211^{*}$ & $-1,031$ & 105 \\
\hline & $(0.0752)$ & $(2,392)$ & $(1,236)$ & $(367)$ & $(5,344)$ & $(1,021)$ & $(150)$ \\
\hline R-squared & 0.009 & 0.004 & 0.006 & 0.007 & 0.003 & 0.000 & 0.004 \\
\hline \multicolumn{8}{|c|}{ Panel B: Treatment on the (Instrumented) Treated } \\
\hline \multirow[t]{2}{*}{ Treatment Group } & $0.647^{* * *}$ & $13,677^{*}$ & $8,282^{* *}$ & $2,832^{* * *}$ & 24,133 & 825 & $842^{*}$ \\
\hline & $(0.222)$ & $(7,176)$ & $(3,703)$ & $(1,090)$ & $(16,126)$ & $(3,070)$ & $(446)$ \\
\hline \multirow[t]{2}{*}{ Constant } & $0.134^{*}$ & 2,689 & $2,442^{*}$ & $1,128 * * *$ & $-10,453^{*}$ & $-1,039$ & 97 \\
\hline & $(0.0755)$ & $(2,440)$ & $(1,259)$ & $(371)$ & $(5,484)$ & $(1,044)$ & $(151)$ \\
\hline Control Group Mean & 0.140 & 2,826 & 2,525 & 1,157 & $-10,211$ & $-1,030$ & 105 \\
\hline Winsorized & None & None & Top $1 \%$ & Top 5\% & None & Top \& Bottom 1\% & Top \& Bottom 5\% \\
\hline Observations & 871 & 871 & 871 & 871 & 871 & 871 & 871 \\
\hline
\end{tabular}

Notes: This table replicates the specification in Table 4 without controlling for "Prior Balance" in their savings account. All outcomes are measured between August and October 2009, the duration of the Feedback Message Experiment. Net new savings $=($ deposits - withdrawals) during that period. Coefficients of OLS regressions in Panel A and coefficients of two-stage least squares in Panel B. All monetary figures in Chilean pesos. 500 Chilean pesos = approximately 1 USD. Level of significance: ${ }^{*} p<0.1,{ }^{* *} p<0.05$, $* * * p<0.01$ 
Table A7: Effects of the Feedback Message Experiment by Treatment Assignment in the Peer Group Experiment

\begin{tabular}{|c|c|c|c|c|}
\hline & $\begin{array}{c}(1) \\
\text { Take-up }\end{array}$ & $\begin{array}{c}(2) \\
\text { Number of Deposits }\end{array}$ & $\begin{array}{c}(3) \\
\text { Amount Deposited }\end{array}$ & $\begin{array}{c}(4) \\
\text { Net New Savings }\end{array}$ \\
\hline \multirow[t]{2}{*}{ SMS Treatment $\times$ Peer Group Treatment } & -0.0810 & 0.0930 & $-7,313$ & 8,161 \\
\hline & $(0.0589)$ & $(0.189)$ & $(6,029)$ & $(13,479)$ \\
\hline \multirow[t]{2}{*}{ SMS Treatment } & $0.455^{* * *}$ & 0.222 & $9,839^{* *}$ & 4,831 \\
\hline & $(0.0455)$ & $(0.146)$ & $(4,655)$ & $(10,407)$ \\
\hline \multirow[t]{2}{*}{ Peer Group Treatment } & 0.0162 & 0.114 & 3,086 & $-8,203$ \\
\hline & $(0.0481)$ & $(0.155)$ & $(4,925)$ & $(11,012)$ \\
\hline \multirow[t]{2}{*}{ Constant } & $-1.18 \mathrm{e}-14$ & 0.0702 & 917 & $-5,136$ \\
\hline & $(0.0379)$ & $(0.122)$ & $(3,874)$ & $(8,662)$ \\
\hline R-squared & 0.191 & 0.014 & 0.006 & 0.003 \\
\hline Control Group Mean & 0.010 & 0.140 & 2,826 & $-10,211$ \\
\hline Observations & 871 & 871 & 871 & 871 \\
\hline
\end{tabular}

Notes: "SMS Treatment" is a dummy variable indicating random assignment to either of the treatment groups in the Feedback Message Experiment. "Peer Group Treatment" is a dummy variable indicating random assignment to the Peer Group Treatment in Experiment 1. Dependent variables are a dummy variable for take-up of the Feedback Message Treatment, number of deposits, amount of deposits and amount of new savings, respectively. All outcomes are measured between August and October 2009, the duration of the Feedback Message Experiment. Net new savings = (deposits - withdrawals) during that period. Values in Chilean pesos. 500 Chilean pesos = approximately 1 USD. Level of significance: ${ }^{*} p<0.1,{ }^{* *} p<0.05,{ }^{* * *} p<0.01$ 
Table A8: Effects of the Feedback Message Experiment (with endogenous controls)

\begin{tabular}{|c|c|c|c|c|}
\hline & $\begin{array}{c}(1) \\
\text { Take-up }\end{array}$ & $\begin{array}{c}(2) \\
\text { Number of } \\
\text { Deposits }\end{array}$ & $\begin{array}{c}(3) \\
\text { Amount } \\
\text { Deposited }\end{array}$ & $\begin{array}{c}(4) \\
\text { Net New } \\
\text { Savings }\end{array}$ \\
\hline \multicolumn{5}{|l|}{ Panel A: Prior Number of Deposits } \\
\hline SMS Treatment $\times$ Prior Number of Deposits & $\begin{array}{c}0.00549 \\
(0.00753)\end{array}$ & $\begin{array}{l}0.0560^{* *} \\
(0.0224)\end{array}$ & $\begin{array}{c}4,028^{* * *} \\
(722)\end{array}$ & $\begin{array}{c}3,057^{*} \\
(1,718)\end{array}$ \\
\hline Treatment Group & $\begin{array}{c}0.401^{* * *} \\
(0.0310)\end{array}$ & $\begin{array}{c}0.177^{*} \\
(0.0923)\end{array}$ & $\begin{array}{c}-566 \\
(2,976)\end{array}$ & $\begin{array}{c}5,276 \\
(7,080)\end{array}$ \\
\hline Prior Number of Deposits & $\begin{array}{l}0.000790 \\
(0.00607)\end{array}$ & $\begin{array}{c}0.0906^{* * *} \\
(0.0180)\end{array}$ & $\begin{array}{c}635 \\
(582)\end{array}$ & $\begin{array}{l}-1,842 \\
(1,384)\end{array}$ \\
\hline Constant & $\begin{array}{l}0.00885 \\
(0.0251)\end{array}$ & $\begin{array}{l}0.00503 \\
(0.0747)\end{array}$ & $\begin{array}{c}1,877 \\
(2,407)\end{array}$ & $\begin{array}{l}-7,458 \\
(5,727)\end{array}$ \\
\hline R-squared & 0.190 & 0.153 & 0.125 & 0.006 \\
\hline \multicolumn{5}{|c|}{ Panel B: Prior Amount Deposited (in 1000s of pesos) } \\
\hline SMS Treatment $\times$ Prior Amount Deposited & $\begin{array}{r}-0.0000371 \\
(0.000153)\end{array}$ & $\begin{array}{c}0.00104^{* *} \\
(0.000490)\end{array}$ & $\begin{array}{c}191^{* * * *} \\
(13)\end{array}$ & $\begin{array}{c}508^{* * *} \\
(17)\end{array}$ \\
\hline Treatment Group & $\begin{array}{c}0.411^{* * *} \\
(0.0295)\end{array}$ & $\begin{array}{l}0.228^{* *} \\
(0.0942)\end{array}$ & $\begin{array}{l}-1,257 \\
(2,542)\end{array}$ & $\begin{array}{c}-10,873^{* * *} \\
(3,254)\end{array}$ \\
\hline Prior Amount Deposited & $\begin{array}{c}-0.00000436 \\
(0.0000931)\end{array}$ & $\begin{array}{c}0.000145 \\
(0.000298)\end{array}$ & $\begin{array}{c}5 \\
(8)\end{array}$ & $\begin{array}{c}-547^{* * *} \\
(10)\end{array}$ \\
\hline Constant & $\begin{array}{c}0.0102 \\
(0.0237)\end{array}$ & $\begin{array}{c}0.135^{*} \\
(0.0759)\end{array}$ & $\begin{array}{c}2,606 \\
(2,046)\end{array}$ & $\begin{array}{c}11,954^{* * *} \\
(2,619)\end{array}$ \\
\hline R-squared & 0.188 & 0.020 & 0.291 & 0.767 \\
\hline \multicolumn{5}{|l|}{ Panel C: Prior Balance (in 1000s of pesos) } \\
\hline SMS Treatment $\times$ Prior Balance & $\begin{array}{l}-0.000159 \\
(0.000295)\end{array}$ & $\begin{array}{c}0.00324^{* * *} \\
(0.000939)\end{array}$ & $\begin{array}{c}496^{* * *} \\
(23)\end{array}$ & $\begin{array}{c}817^{* * *} \\
(33)\end{array}$ \\
\hline Treatment Group & $\begin{array}{l}0.411^{* * *} \\
(0.0291)\end{array}$ & $\begin{array}{l}0.227^{* *} \\
(0.0928)\end{array}$ & $\begin{array}{c}-202 \\
(2,253)\end{array}$ & $\begin{array}{l}-2,439 \\
(3,285)\end{array}$ \\
\hline Prior Balance & $\begin{array}{c}-0.00000281 \\
(0.000154)\end{array}$ & $\begin{array}{l}0.0000739 \\
(0.000492)\end{array}$ & $\begin{array}{c}-0.458 \\
(12)\end{array}$ & $\begin{array}{c}-901.9^{* * *} \\
(17)\end{array}$ \\
\hline Constant & $\begin{array}{c}0.0101 \\
(0.0235)\end{array}$ & $\begin{array}{c}0.139^{*} \\
(0.0749)\end{array}$ & $\begin{array}{c}2,833 \\
(1,819)\end{array}$ & $\begin{array}{c}3,108 \\
(2,653)\end{array}$ \\
\hline R-squared & 0.188 & 0.029 & 0.431 & 0.757 \\
\hline Control Group Mean & 0.010 & 0.140 & 2,826 & $-10,211$ \\
\hline Observations & 871 & 871 & 871 & 871 \\
\hline
\end{tabular}

Notes: This table calculates the effect of the Feedback Message Experiment with endogenous control variables. "SMS Treatment" is a dummy variable indicating random assignment to either of the treatment groups in the Feedback Message Experiment. All outcomes are measured between August and October 2009, the duration of the Feedback Message Experiment. Net new savings is (deposits - withdrawals) during that period. Values in Chilean pesos. 500 Chilean pesos $=$ approximately 1 USD. Level of significance: ${ }^{*} p<0.1,{ }^{* *} p<0.05,{ }^{* * *} p<0.01$ 
Table A9: Effects of the Peer Group Treatment for the Feedback Message Sample

\begin{tabular}{lccc}
\hline \hline & $(1)$ & $(2)$ & $(3)$ \\
& \# of Deposits & Amount Deposited & Net New Savings \\
\hline Self-Help Peer Groups & $0.863^{* * *}$ & 8,065 & $10,275^{*}$ \\
& $(0.185)$ & $(5,255)$ & $(5,433)$ \\
High-Interest Treatment & 0.0149 & 6,813 & 5,829 \\
& $(0.104)$ & $(4,296)$ & $(4,349)$ \\
Constant & $0.269^{* * *}$ & $4,752^{* * *}$ & $-2,715$ \\
& $(0.0771)$ & $(1,799)$ & $(3,804)$ \\
\hline R-squared & 0.051 & 0.002 & 0.003 \\
Observations & 871 & 871 & 871 \\
\hline \hline
\end{tabular}

Notes: This table calculates the effects of the Peer Group Experiment for August to October 2008 among the sample of the 871 participants who also ended up participating in the Feedback Message Experiment. Net new savings = (deposits - withdrawals) during that period. Standard errors clustered at the group level in parentheses. Monetary figures in Chilean pesos. 500 Chilean pesos = approximately 1 USD. Level of significance: ${ }^{*} p<0.1,{ }^{* *} p<0.05,{ }^{* * *} p<0.01$ 
Table A10: Choice of Savings Buddy

\begin{tabular}{lcc}
\hline \hline & Frequency & Percent \\
\hline Why did you choose your Savings Buddy? & & \\
Because my Savings Buddy ... & 18 & 12.24 \\
$\ldots$ and I save together in the same account. & 45 & 30.61 \\
$\ldots$ is very strict and will motivate me to comply with my savings goals. & 4.76 \\
$\ldots$ is very relaxed and will understand if I do not reach my savings goals. & 7 & 28.57 \\
$\ldots$ is very close to me and I share my financial information with them. & 42 & 19.05 \\
$\ldots$. is a role model when it comes to savings, very organized and always & 28 & \\
complies with their savings goals. & & 2.72 \\
Other & 4 & 2.04 \\
No response & 3 & \\
Number of observations & 147 & \\
\hline What is your relationship to your Savings Buddy? & & \\
\hline Partner & 37 & 25.17 \\
Parent & 8 & 5.44 \\
Child & 48 & 32.65 \\
Other relative & 20 & 13.61 \\
Close friend & 25 & 17.01 \\
Neighbor & 3 & 2.04 \\
Other & 4 & 2.72 \\
No response & 2 & 1.36 \\
\hline Number of observations & 147 & 100.00 \\
\hline \hline
\end{tabular}


Table A11: Reasons Not to Transfer Money into High-Interest Account

\begin{tabular}{|l|r|}
\hline $\begin{array}{l}\text { Mental accounting ("Because the alternative account is destined towards a } \\
\text { specific goal that I do not want to mix with the other savings account") }\end{array}$ & $66 \%$ \\
\hline $\begin{array}{l}\text { Uncertainty ("Because I am not sure whether the favorable conditions of the } \\
\text { account in the study will continue") }\end{array}$ & $19 \%$ \\
\hline Trust ("The other bank is more trustworthy") & $16 \%$ \\
\hline Distance ("The other bank is closer") & $12 \%$ \\
\hline Interest rate ("The other account has a higher interest rate") & $11 \%$ \\
\hline Cost of withdrawing and redepositing & $9 \%$ \\
\hline Having an outstanding loan at the other bank & $8 \%$ \\
\hline
\end{tabular}

Notes: This table shows the percentage of individuals among those who did not transfer money into the high-interest account who indicated this reason as "very important." 